MARTIN MAAIETTA ENERGY SYSTEMS LIBPAPAES

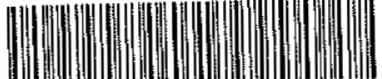

$34456 \quad 0254493 \quad$

\title{
The Global Carbon Dioxide Problem
}

\author{
C. F. Baes, Jr. \\ H. E. Goeller \\ J. S. Olson \\ R. M. Rotty
}

This document has been reviewed and is determined to be APPROVED FOR PUBLIC RELEASE.

Name/Title: Leesa Laymance/ORNL-TIO

Date: $1 / 12 / 2021$

\section{OAK RIDGE NATIONAL MABORATORY}

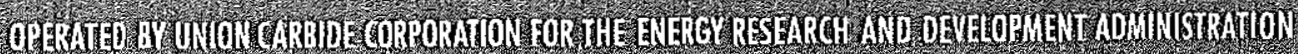




\begin{tabular}{|c|}
\hline Printed in the United States of America. Available from \\
National Technical Information Service \\
U.S. Department of Commerce \\
5285 Port Royal Road, Springfield, Virginia 22161 \\
Price: Printed Copy $\$ 5.00:$ Microfiche $\$ 2.25$
\end{tabular}

This report was prepared as an account of work sponsored by the United States Government. Neither the United States nor the Energy Research and Development Administration/United States Nuclear Regulatory Commission, nor any of their employees, nor any of their contractors, subcontractors, or their employees, makes any warranty, express or implied, or assumes any legal liability or responsibility for the accuracy, completeness or usefulness of any information, apparatus, product or process disclosed, or represents that its use would not infringe privately owned rights. 

ORNL-5194

\section{THE GLOBAL CARBON DIOXIDE PROBLEM}

C. F. Baes, Jr., Chemistry Division, ORNL

H. E. Goeller, Program Planning \& Analysis Office, ORNL

J. S. 01 son, Environmental Sciences Division, ORNL

R. M. Rotty, Institute for Energy Analysis, ORAU

\section{AUGUST 1976}

OAK RIDGE NATIONAL LABORATORY

Oak Ridge, Tennessee 37830

operated by

UNION CARBIDE CORPORATION

for the

ENERGY RESEARCH AND DEVELOPMENT ADMINISTRATION

MAPTIN MAARETTA ENERGY SYSTEMS UBRARIES

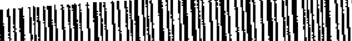

(I)

3445602544931 

Table of Contents

Acknowledgement. . . . . . . . . . . . . . . . . . . . iv

Abstract . . . . . . . . . . . . . . . . . . . . . v

1. Introduction; Summary, and Recommendations . . . . . . . . . . . 1

1.1 Introduction. . . . . . . . . . . . . . . . 1

1.2 Summary . . . . . . . . . . . . . . . . . 3

1.3 Recommendations . . . . . . . . . . . . . . . 5

1.3.1 Understanding the Carbon Cycle . . . . . . . . . . 6

1.3.2 Predicting Climate Change. . . . . . . . . . 6

1.3.3 Evaluating the Consequences of Climate Change. . . . . . 6

2. State of Knowledge . . . . . . . . . . . . . . . 8

2.1 Evolution of the Carbon Cycle . . . . . . . . . . . 8

2.2 Regions and Quantities of Carbon. . . . . . . . . . . 10

2.2.1 Atmosphere . . . . . . . . . . . . . 10

2.2.2 Terrestrial Ecosystems . . . . . . . . . . 12

2.2 .3 0ceans................. . . 13

2.3 Circulation of Carbon . . . . . . . . . . . . . 17

2.3.1 Anthropogenic Fluxes . . . . . . . . . . . . 17

2.3.2 Terrestrial Ecosystem Fluxes . . . . . . . . . . 19

2.3.3 Ocean Fluxes . . . . . . . . . . . . . . 25

2.4 Predicting Future Levels of $\mathrm{CO}_{2}$. . . . . . . . . . . . . 30

2.5 Atmospheric $\mathrm{CO}_{2}$ and Climate Change. . . . . . . . . . 39

2.6 Impacts of Climate Change . . . . . . . . . . . . 45

2.6.1 General Ecological Considerations. . . . . . . . . 45

2.6.2 Effects on Agriculture . . . . . . . . . . . 47

2.6.3 Shoreline Changes and Hydrologic Effects . . . . . . 47

2.6 .4 other Impacts. . . . . . . . . . . . . . 48

3. On-Going Research and Funding. . . . . . . . . . . . . . . 50

4. Recommendations and Conclusions. . . . . . . . . . . . . 59

4.1 Understanding the Carbon Cycle. . . . . . . . . . . . 60

4.2 Predicting Climate Change . . . . . . . . . . . . . 61

4.3 Evaluating the Consequences of Climate Change . . . . . . . 63

4.4 Conclusions . . . . . . . . . . . . . . . 65

References . . . . . . . . . . . . . . . . . 67 
ACKNOWLEDGEMENT

During the preparation of this report, we have benefited greatly. from discussions with a number of individuals. We wish especially to thank: W. Broecker of the Lamont-Doherty Geological Observatory; V. Ramanathen of the Langely Research Center; L. Machta, Director of the Air Resources Laboratories, NOAA; J. M. Mitche11 of the Environmental Data Service, NOAA; S. Manabe of the Geophysical Fluid Dynamics Laboratory, NOAA; F. A. Gifford, Director of the Atmospheric Turbulence and Diffusion Laboratory, NOAA; G. Marland, Institute for Energy Analysis, ORAU; W. F. Harris and B. S. Ausmus, Environmental Sciences Division, ORNL. We are grateful to C. D. Keeling, Scripps Institute of Oceanography, for permission to include as yet unpublished material in Figures 8 and 9 . Finally we appreciate the administrative and secretarial support of the Chemistry Division, the Program Planning and Analysis office, and the Environmental Sciences Division, all of ORNL; and of the Institute for Energy Analysis, Oak Ridge Associated Universities. 
ABSTRACT

The concentration of carbon dioxide in the atmosphere has increased steadily from the pre-industrial value of about $295 \mathrm{ppm}$ in 1860 to the current value of $330 \mathrm{ppm}$. Since the beginning of accurate and regular measurements in 1958, the increase has accounted for about $50 \%$ of the carbon dioxide released by the burning of fossil fuels - currently the latter is $5 \times 10^{9}$ metric tons of carbon per year. The remainder of the flux from the burning of fossil fuel has been balanced by the take-up of carbon dioxide in the oceans and/or the land biota, but since many of the pools and fluxes of the carbon cycle are large compared to the fossil carbon flux, it is not clear how the carbon cycle has accomplished this. Yet many of these pools and fluxes are in turn dwarfed by the economic reserves of fossil fuel (perhaps $7,400 \times 10^{9}$ tons of carbon). If the growth in the production of carbon dioxide from fossil fuels (typically $4 \%$ per year) continues, an appreciable fraction of this reserve could be consumed in the next 100 years and the resulting atmospheric concentration of $\mathrm{CO}_{2}$ could reach several times its pre-industrial value. Estimates of the consequent warming ("greenhouse") effect indicate increases in the average surface temperature of the earth that range from possibly acceptable to catastrophic. Clearly it is necessary to foresee more accurately the consequences of the continued use of fossil fuels by: (1) learning more of the carbon cycle (particularly ocean circulation, the effect of $\mathrm{CO}_{2}$ on photosynthesis, and the effect of changing patterns of land use) in order to judge how the airborne fraction of the fossil carbon flux will change in the future; (2) most importantly, learning more about the climatic (particularly regional) effects of increased atmospheric $\mathrm{CO}_{2}$ through a greatly increased and integrated climate study effort; and (3) learning how to predict the full impact of a given change in regional climate on man, his environment, and his society. Only then can we judge how rapid].y we can safely use our fossil fuel reserves. 



\section{INTRODUCTION, SUMMARY, AND RECOMMENDATIONS}

Most scientists viewing the accelerated burning of fossil fuels now agree that excess $\mathrm{CO}_{2}$ will warm the earth's surface temperature significantly. It seems very improbable that opposing factors would nicely counteract the indirect climatic and ecological changes that would follow, or prevent severe economic and other social costs over wide regions.

During the remainder of the twentieth century it may be impossible to sort out such impacts from the fluctuations of weather that are widely suffered but poorly understood. But the urgency which we sense from the present study is that decisions of the next few years may block or put off humanity's choices for avoiding drastic changes in the early or middle decades of the 21st century.

Our report strives to link important aspects of the global carbon dioxide problem which too commonly are treated only separately. The present section (1) outlines these aspects, (2) summarizes the main conclusions, and (3) recommends actions to improve on judgment of the risks and reduce the human costs of change.

\subsection{Introduction}

In view of ERDA's commitment to the increased use of fossil fuels to meet our nation's energy' needs, it seems appropriate for us to review the present state of the problem of predicting the environmental impact of anthropogenic carbon dioxide. In performing such a review our objective will be to (1) determine the present state of the relevant knowledge; (2) summarize the important current research efforts, the principal investigators, and the sources of their funding; and (3) determine what important areas of investigation remain that might be appropriate for support by ERDA.

In reviewing the present state of knowledge we will consider the atmospheric, oceanic, and terrestrial reservoirs of the carbon cycle and the important fluxes among them (Fig. 1). We will be concerned with the effect of the increasing anthropogenic flux to the atmospheric reservoir on the carbon dioxide content of the atmosphere. This will depend to some extent of course on how the other fluxes change at the same time, both as 


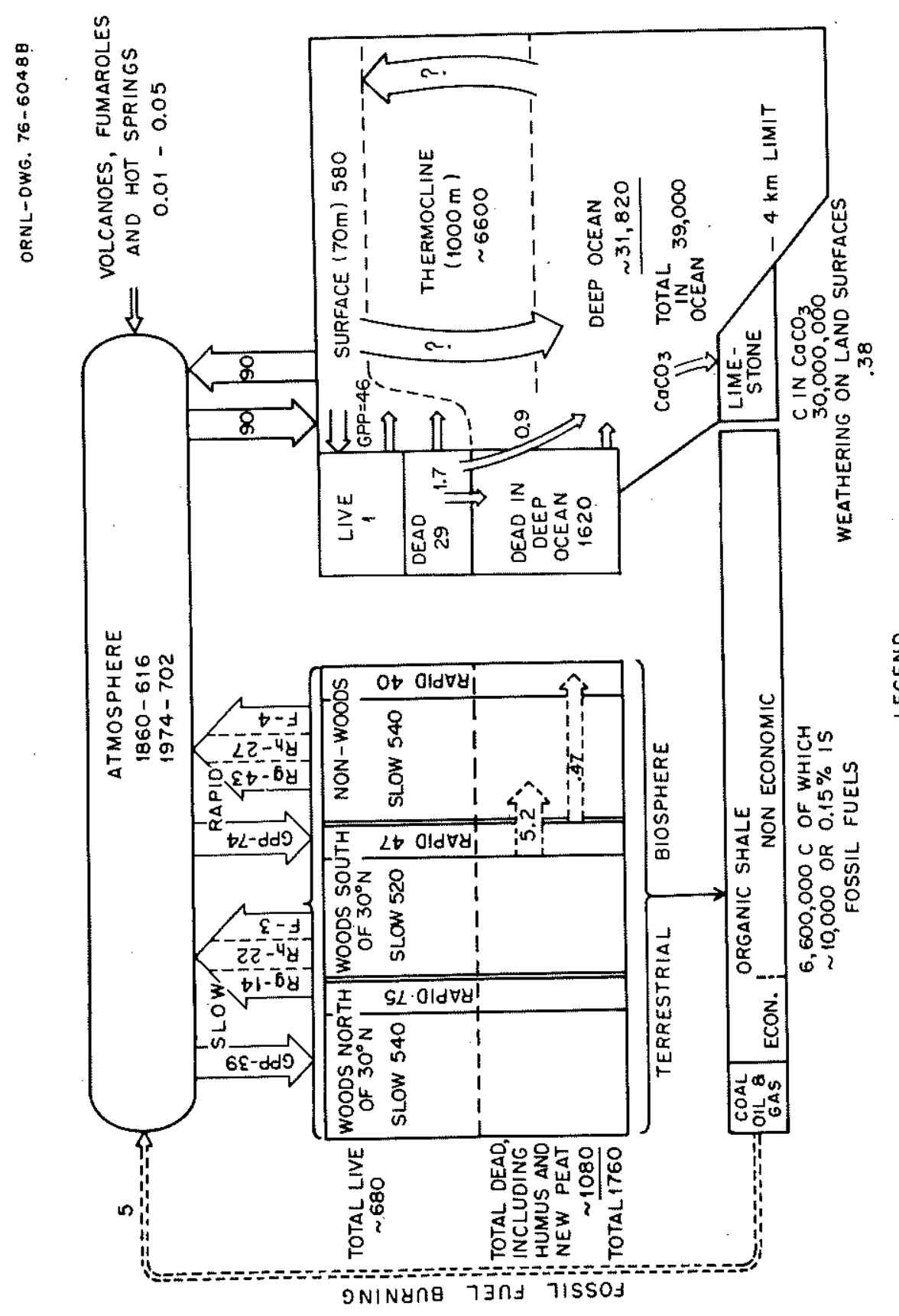

荀

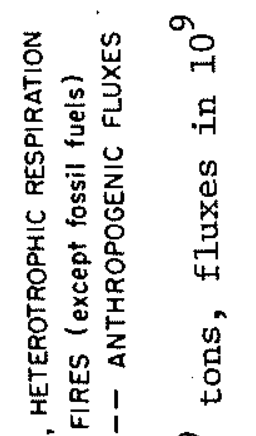
\begin{tabular}{l|l}
$x^{x}$ & o \\
$x^{2}$ &
\end{tabular}

읜ㅎㅇ은

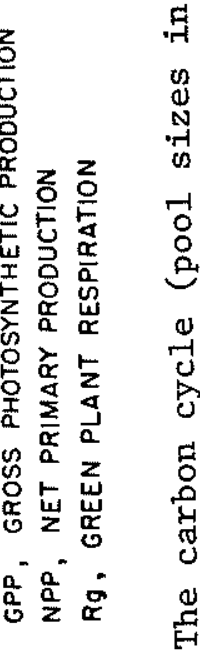

ri

$\underset{\substack{\infty \\ i=1}}{i=1}$ 
a result of the anthropogenic flux and from natural causes. Finally we shall consider what is known of the possible climatic effect of the projected increase in atmospheric $\mathrm{CO}_{2}$.

It is apparent that the uncertainties along the way and in the final assessment of the impact of anthropogenic carbon dioxide are considerable; hence, our review will be concerned primarily with the more important and the more uncertain aspects of the problem. Our summary of on-going research will reflect our judgments of what studies seem most likely to reduce the major uncertainties, and our recommendations of needed additional work will follow naturally from the same judgments.

\subsection{Summary}

The rate at which $\mathrm{CO}_{2}$ is emitted by volcanic activity and other geothermal venting, while important over the long history of the earth (Fig. 2, p. 9), is small ( $0.04 \times 10^{9}$ tons $\mathrm{C} / \mathrm{yr}$ ) compared to the rate of fossil carbon burning (presently $\sim 5 \times 10^{9}$ tons $c / y r$ ). The latter flux, in turn, is small compared to most of the amounts and fluxes in and among the atmospheric, terrestrial, and oceanic regions of the carbon cycle (Fig. 1, p. 2).

Yet quite clearly, because of the fossil-fuel flux, the atmospheric $\mathrm{CO}_{2}$ level has exhibited a secular increase from the pre-industrial value of $\sim 295 \mathrm{ppm}$ to the present value of $\sim 330 \mathrm{ppm}$. The accurate measurements that have been made since 1958 (Fig. 3, p. 11) show a fairly uniform and accelerating increase (upon which is superimposed an annual fluctuation from photosynthesis and other seasonal effects) which has remained equivalent to about $50 \%$ of the cumulative fossil fuel consumption (Fig. 7, p. 20). How the natural carbon cycle has been perturbed by the fossil carbon flux to remove, in effect, $50 \%$ of it from the atmosphere is not yet clear. The net flux between the atmosphere and the land is determined mainly by the relatively small difference between gross photosynthetic production and the sum of respiration and fires (Table 1, p. 21). It may also be affected appreciably by changing patterns of man's use of the land. In the long run a net flux to the oceans is expected because $\mathrm{CO}_{2}$ should react there with carbonate ion $\left(\mathrm{CO}_{3}{ }^{2}\right)$ and with calcium carbonate sediments $\left(\mathrm{CaCO}_{3}\right)$ to maintain much of the oceans near saturation with $\mathrm{CaCO}_{3}$. The 
ultimate capacity of the ocean and its sediments to take up $\mathrm{CO}_{2}$ far exceeds that needed, but only a relatively thin $(\sim 70 \mathrm{~m})$, well mixed surface layer can react quickly with atmospheric $\mathrm{CO}_{2}$; its capacity is limited primarily by its small supply of $\mathrm{CO}_{3}=$ ion. The net rate of $\mathrm{CO}_{2}$ uptake by the oceans should therefore be determined largely by the rate of circulation and mixing between surface waters and the deep oceans. The rate of mixing, partly in polar regions of descending surface waters and elsewhere through a stagnant layer ( $\sim 1000 \mathrm{~m}$ thick, called the thermocline), may be sufficient to account for the 50\% uptake of the fossil carbon flux, but this has not yet been established. A portion could be going to increase the terrestrial biomass, despite man's conversion of organic material to $\mathrm{CO}_{2}$.

The future levels of atmospheric $\mathrm{CO}_{2}$ will depend primarily on the rate of consumption of fossil fuel, and to a lesser extent on land use patterns and on the fraction that is stored in the oceans. With brief interruptions for the two world wars and the great depression, the production of $\mathrm{CO}_{2}$ from fossil fuels has increased with an annual rate of $4.3 \%$ (Fig. 6, p. 18). The upper curve in Figure 12 (p. 40) represents projected future levels of atmospheric $\mathrm{CO}_{2}$ if this high growth rate were to continue, with allowance for depletions of the economic reserves (Eq. 11, p. 36). The lower curve is given by a $2 \%$ annual growth rate to the year 2025 followed by a symmetrical decrease. If all the economically recoverable fossil fuel were burned and $50 \%$ of the $\mathrm{CO}_{2}$ produced remained in the atmosphere, the $\mathrm{CO}_{2}$ concentration would ultimately reach nearly 7 times the pre-industrial value.

The climate changes that would be produced by a given amount and rate of increase of atmospheric $\mathrm{CO}_{2}$ are quite uncertain. Models of various complexity suggest that the temperature response is logarithmic; i.e., that for each doubling of the concentration of $\mathrm{CO}_{2}$ there will be about the same increase $(\Delta T)$ in the global average temperature. The more sophisticated models predict that the temperature increases will be greater at high latitude. The present best estimate places $\Delta \mathrm{T}$ in the range $1.5^{\circ}$ to $3^{\circ} \mathrm{K}$ per doubling. However, because some important feedback mechanisms are missing from even the best models (e.g., decreasing ice and snow cover, changing cloud cover, ocean coupling, and biota response), we suggest a wider range of $1^{\circ}$ to $5^{\circ} \mathrm{K}$ per doubling. The resulting possible increase in 
the global average temperature over the next 100 years (Fig. 13, p. 44) ranges from about $1^{\circ} \mathrm{K}$ (comparable to the rate of natural change) to a catastrophic $11^{\circ} \mathrm{K}$. The often-mentioned cooling produced simultaneously by the emission of particulates is by no means a certain effect and at best it seems likely to be a local one.

The accompanying changes in regional climate and the consequent impacts on man, his environment, and his institutions are, of course, also uncertain. While some changes will be beneficial, most are likely to be deleterious for the simple reason that species and crops are optimized to existing conditions. As a result biological productivity will 1ikely be decreased, at least temporarily, in many regions by rapid changes in climate. This could have dire effects on a world agriculture pressed to its limits of productivity by a growing population. Where regional climates become drier, changes in hydrology and a lowering of lake levels could be economically costly. Over possibly a much longer time, loss of coastal land to a rising sea fed by a melting glacial ice could have large impacts. The chains of consequences - ecological to economic to social and political - are difficult indeed to foresee, yet they must be anticipated in time for remedial actions.

Perhaps the most serious matter is an ethical question. Should we and our children be making a commitment for scores of generations to follow by consuming the fossil carbon reserves and producing future changes in the world environment, some impossible to reverse for many centuries to come?

\subsection{Recommendations}

The recommendations summarized below address three important aspects of the global carbon dioxide problem - (1) the carbon cycle, (2) the effect of increased atmospheric $\mathrm{CO}_{2}$ on climate, and (3) the impact of climate change - which need intensive study. Since the carbon dioxide problem is global, obviously all these recommendations are not directed to ERDA's attention alone. We have marked certain ones, however, because they seemed to us especially appropriate for ERDA's participation (*) or initiation. (**). 
1.3.1 Understanding the Carbon Cycle

1. ${ }^{*}$ Increase monitoring and research programs that give information on the fluxes of $\mathrm{CO}_{2}$ between the atmosphere and the oceans, including: (1) measurements of the excess or deficiency of $\mathrm{CO}_{2}$ in surface water, (2) studies of ocean circulation, and (3) studies of rates of reaction of $\mathrm{CaCO}_{3}$ sediments with dissolved carbon dioxide and bicarbonate.

2. * Increase monitoring and research programs that give information on the fluxes of $\mathrm{CO}_{2}$ between the atmosphere and the land, especially the rate of change of (1) the terrestrial biomass, (2) burning, (3) other turnover of organic carbon, and (4) patterns of land use.

3. ${ }^{* *}$ Develop better models to project the important fluxes of the carbon cycle as a function of assumed future changes in the anthropogenic fluxes of $\mathrm{CO}_{2}$.

\subsubsection{Predicting Climate Change}

1. Monitor climate variables systematically on a world-wide basis, including, (1) improved geographic coverage of the usual meteorological variables, (2) accurate observations of seasonal changes in atmospheric $\mathrm{CO}_{2}$, and (3) further development of satellite monitoring of the atmosphere, especially cloud variables.

2. Initiate a much larger climate study program to predict the effect of $\mathrm{CO}_{2}$ on future climate, including: (1) numerical modeling, (2) physical modeling, (3) basic studies of fluid dynamics, (4) studies of cloud formation and interactions, and (5) statistical analysis of observational data. An effort should be made to attract people from the physical and engineering sciences as well as meteorology and climatology to study climate.

3. Encourage the extensive world-wide cooperation essential for rapid progress through support of the Global Atmospheric Research Program (GARP).

\subsubsection{Evaluating the Consequences of Climate Change}

1. * Collect, compile, and analyze on a regional basis existing and new information on climate, biota, agriculture, natural resources, and economics. 
2. "Develop models that predict the effects of various climate changes for each region, including ecological, economic, and social impacts. 3. ${ }^{* *}$ Validate such models to the fullest extent possible at every stage by applying them to places and times that have produced or are producing observable effects from climate change.

4. ${ }^{* *}$ Seek vigorously the cooperation needed among the diverse organizations and disciplines that have contributions to make to this unprecedented environmental impact study. 


\section{STATE OF KNOWLEDGE}

\subsection{Evolution of the Carbon Cycle}

The contribution of carbon dioxide to the atmosphere and oceans from volcanoes (and from fumaroles, hot springs, and other natural venting) has been very important over the long history of the earth (Fig. 2) but seems to be of relatively minor importance on a year-to-year basis. Originally, in an atmosphere- and ocean-free earth all the terrestrial carbon existed in meteorites and igneous rocks. "Thus far only $1-5 \%$ of this carbon has been released as volatile $\mathrm{CO}_{2}, \mathrm{CO}$, COS, etc., but mostly as $\mathrm{CO}_{2}$. This has been converted largely to limestone ( $82 \%$ ) and to a lesser extent (18\%) the various forms of reduced carbon. At any given time the amount of carbon that resides in and circulates among the atmosphere, biosphere, and oceans is a very small portion $(<0.1 \%)$ of the total carbon in the sedimentary rocks of the 1ithosphere.

Rubey (1951, 1955) and Poldervaart (1955) have argued that it is highly likely that excess volatiles $\left(\mathrm{H}_{2} \mathrm{O}, \mathrm{CO}_{2}, \mathrm{CO}, \mathrm{HCl}, \mathrm{HF}, \mathrm{H}_{2} \mathrm{~S}\right.$, etc.) have been released from the earth's interior rather uniformly over all geologic time $\left(4.6 \times 10^{9}\right.$ years). They propose that an atmosphere (principally $\mathrm{CO}_{2}$ and $\mathrm{N}_{2}$ ) was established early from excess volatiles, and that the volume of the oceans has grown steadily once water vapor was condensed. In a more recent study on the outgassing of volatile elements from the earth's interior, Li (1972) prefers a model based on asymptoicic outgassing in which $95 \%$ of the primary excess volatiles were released in the first $10^{9}$ years. He views the overall outgassing as being steady throughout geologic history, however, because of the recycling of sedimentary (and igneous) rocks through the action of plate tectonics. Bowen's (1966) synthesis indicates that the present annual average release rate of $\mathrm{CO}_{2}$ fxom volcanoes, etc., is $7.7 \times 10^{-5} \mathrm{KgC} / \mathrm{m}^{2}$ of the earth's total surface $\left(5.1 \times 10^{14} \mathrm{~m}^{2}\right)$. This amounts to $0.04 \times 10^{9}$ tons $^{* *}$ of carbon per year. Bowen's

\footnotetext{
*If the present crustal abundance of carbon of $200 \mathrm{ppm}$ in igneous rock holds for the entire mass of the primordial earth $\left(6 \times 10^{21}\right.$ metric tons), there are $1.2 \times 10^{18}$ tons of carbon in the earth. Estimates of present sediment mass range from $1.5 \times 10^{18}$ tons (Poldervaart, 1955) to $2.5 \times 10^{18}$ tons (Garrels et al., 1975), and estimates of the total carbon in sediments range from 12.5 to $62 \times 10^{15}$ tons.

${ }^{* *}$ Here and elsewhere the unit of mass will be the metric ton $\left(10^{6} \mathrm{~g}\right)$.
} 


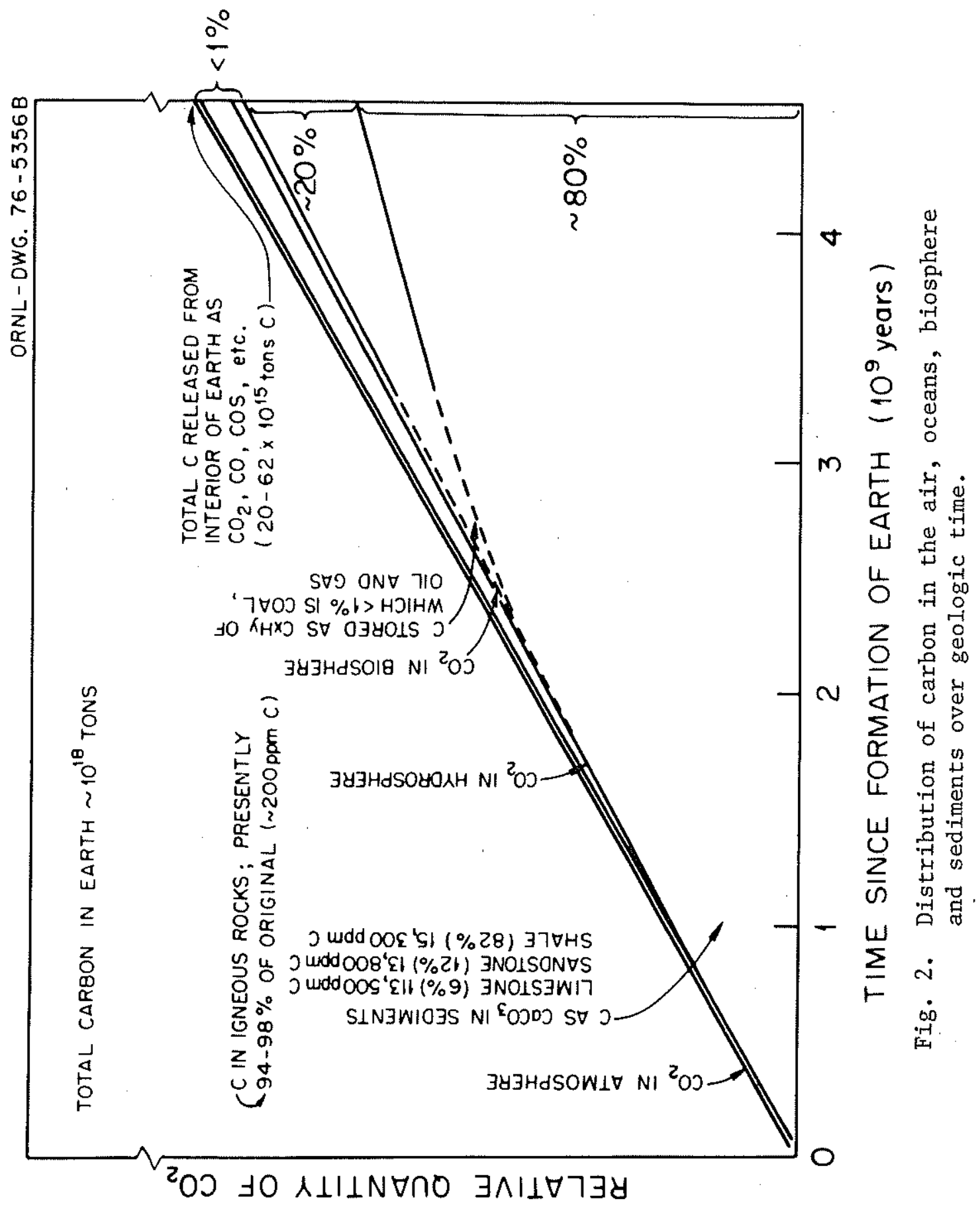


value is in better agreement with Li's model of outgassing than the earlier uniform outgassing model of Rubey and Poldervaart.

Compared to the present annual release of nearly $5 \times 10^{9}$ tons of carbon as $\mathrm{CO}_{2}$ from the burning of fossil fuels (Rotty, 1976), the rate of natural out-gassing of $\mathrm{CO}_{2}$ is nearly insignificant. The accompanying injection of large quantities of volcanic dust into the atmosphere (Mitchell, 1973) appears to have a much greater short-term (several years) effect on climate than does volcanic $\mathrm{CO}_{2}$.

\subsection{Regions and Quantities of Carbon}

The effect of a rapid increase in fossil fuel burning is superimposed on all the other processes in the carbon cycle (Fig. 1). Some understanding of the pools and fluxes of this cycle and the processes that affect them is necessary to properly project atmospheric carbon dioxide content. We consider here the pools of the carbon cycle and in Section 2.3 the fluxes.

\subsubsection{Atmosphere}

The 1.974 atmospheric total of nearly $702 \times 10^{9}$ tons of elemental carbon represents a significant increase from about $616 \times 10^{9}$ tons in 1860, largely due to man's accelerated burning of fossil fuels. Sensitive measurements of atmospheric $\mathrm{CO}_{2}$ (corrected for temporary or local disturbances by land or sea sources), which were begun during the International Geophysical Year (1957), show a regular annual oscillation and a continual annual increase. Figure 3 shows measurements made at Mauna Loa Observatory in Hawaii since 1958. Seasonal variations are clear; the large influence of Eurasian and North American summers is apparent in the drawdown of the atmospheric reservoir of $\mathrm{CO}_{2}$ when seasons are favorable for photosynthesis. " Also, melting of sea ice during warm seasons allows greater ocean uptake from the atmosphere, while respiration of the biota and burning of fossil fuels are proceeding (with shifting rates) through the year.

Mauna Loa data are not alone in showing this buildup of atmospheric carbon dioxide and the seasonal variations. Measurements made at different

\footnotetext{
* These variations have been analyzed by Hall et al., (1975).
} 


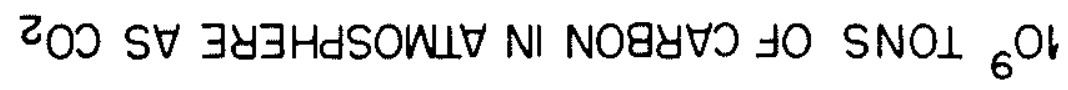

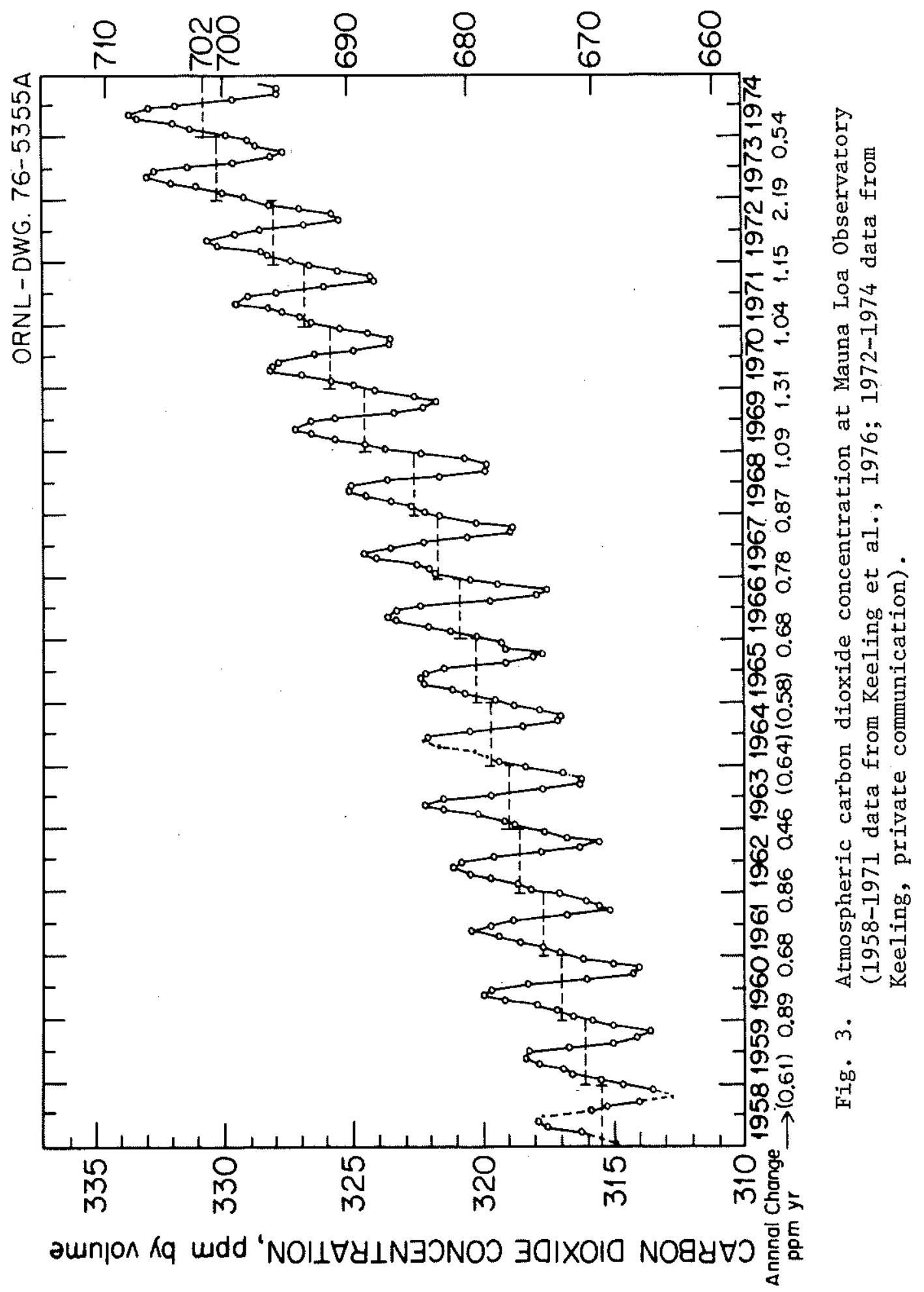


locations from $73^{\circ} \mathrm{N}$ to $90^{\circ} \mathrm{S}$ (e.g., Barrow, Alaska; Aircraft over Sweden; South Pole) show larger amplitudes at the most northern stations and lesser amplitudes farther south. Differences in the measuring instruments and in calibration techniques make comparisons of absolute concentrations between these stations difficult, but in all cases the upward trend is strongly evident.

It has been estimated that about half of the carbon dioxide produced from fossil fuels is accounted for in the atmospheric increases indicated by the trend of Figure 3 .

\subsubsection{Terrestrial Ecosystems}

Part of the excess carbon unaccounted for in the atmosphere may be accumulating in terrestrial organic matter. The pools and fluxes are large enough, however, that estimates of the net imbalance of the opposing rates requires a good overall knowledge of the terrestrial portion of the carbon cycle.

Nonfossil organic carbon pools are dominated by materials with slowly exchanging carbon, totaling more than $10^{12}$ tons. Of this we estimate: approximately $1000 \times 10^{9}$ tons in dead organic material, i.e., humus and recent peat; and about $600 \times 10^{9}$ tons of carbon in the larger, long-lived stems and roots of vegetation. * The present estimate for slowly exchanging live organic material is somewhat larger than the $500 \times 10^{9}$ tons included in 01son (1970a) and SCEP (1970).

We estimate the pools of rapidly exchanging carbon (consisting of plant leaves, small branches, and roots; litter; invertebrates; decomposers) to total $160 \times 10^{9}$ tons. This is larger than a previous estimate in SCEP (82 $\times 10^{9}$ tons), but is still divided about equally between live and dead parts.

\footnotetext{
* Our value for dead material is almost as great as that of Kovda and Yakushevskaya (1971) for total humus (1080 × $10^{9}$ tons). Bazilevich (1974) separately estimated recent peat having a carbon equivalent of about $88 \times 10^{9}$ tons. Reiners et al., (1973) allocated only $700 \times 10^{9}$ to dead organic carbon on land, but essentially made up the difference with $330 \times 10^{9}$ in freshwaters; presumably the latter figure includes many bogs which are associated with small lakes and swamps. Perhaps there are several hundred billion tons of carbon in buried soil horizons and peat which are not included in the inventory of Table 1 , but which have a still slower turnover than the slowly exchanging materials which are included.
} 
These pools of slowly and rapidly exchanging carbon, totaling over $1700 \times 10^{9}$ tons, are allocated to three groups of ecosystems in Table 1 (page 21): (1) Northern Woods $\left(610 \times 10^{9}\right.$ tons), above $30^{\circ} \mathrm{N}$ latitude; (2) Nonwoody Ecosystems (580 × $10^{9}$ tons), integrated over all kinds and latitudes; and (3) Southern Woods ( $570 \times 10^{9}$ tons), below $30^{\circ} \mathrm{N}$ latitude. The wooded ecosystems consist of forests, open woodlands, and wet thickets, including woody swamps. The nonwoods consist of grassland, desert or semidesert, tundra, agricultural, suburban, and urban areas (Fig. 4).

Both categories of woods together now occupy about $50 \times 10^{6} \mathrm{~km}^{2}$ of the land surface ( $1 / 3$ of the $148 \times 10^{6} \mathrm{~km}^{2}$ total, Fig. 4) and obviously carry higher biomass and carbon per unit area on the average than nonwoods. About $15 \times 10^{6} \mathrm{~km}^{2}$ of land is ice-covered. The carbon inventory of the remaining terrestrial ecosystems plus lake and river systems are spread rather unevenly over about $83 \times 10^{6} \mathrm{~km}^{2}$. Approximate areas, proportions and locations are suggested by the bar widths in Figure 4 and mapped zones on Figure 5. Complementary approaches taken by Lieth and Whittaker (1975) and their chapter contributors tend to confirm these general totals and patterns, but many questions of statistics and interpretation need to be resolved in improved compilations and models of organic carbon budgets. Lower estimates of carbon pools (Eriksson and Welander, 1956; Bolin, 1970; Bowen, 1966; Garrels et a1., 1975) seem to depend on a body of older literature, some dating to the last century.

Only very small fractions of all the terrestrial carbon pools are represented by animals--short-lived and long-lived (including man).

\subsubsection{Oceans}

For modeling purposes the ocean is often divided into several regions (Broecker, 1974; Stuiver, 1973). One is the surface layer, extending to a depth averaging about $70 \mathrm{~m}$, heated by the sun and agitated by the wind such that it is relatively well mixed and on the average approximately at equilibrium with the atmospheric $\mathrm{CO}_{2}$. Beneath this is a relatively stagnant region, the thermocline, stabilized by a decreasing temperature and an increasing density to a depth of about $1000 \mathrm{~m}$. Below this is the much larger region of the deep ocean, isolated from the surface waters by the thermocline. When the surface waters are sufficiently cold and/or saline, 


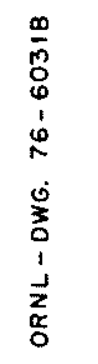

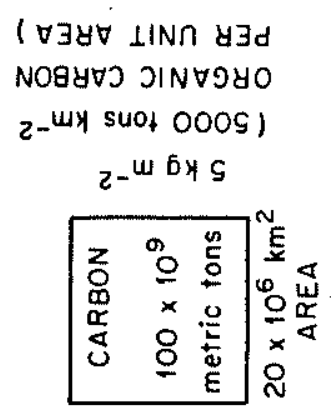

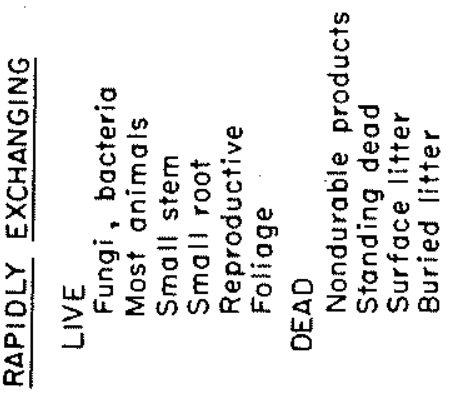

MONS ONV SY3IJV79

SWVJYLS ONV SJYV7

NY3HLINOS

SOOOM

NY 3 HIYON

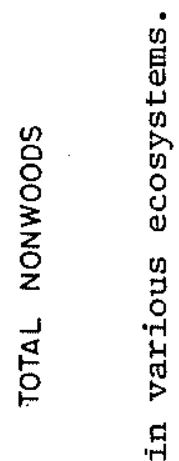

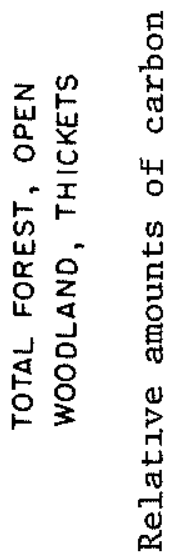

$\dot{y}$

眪 


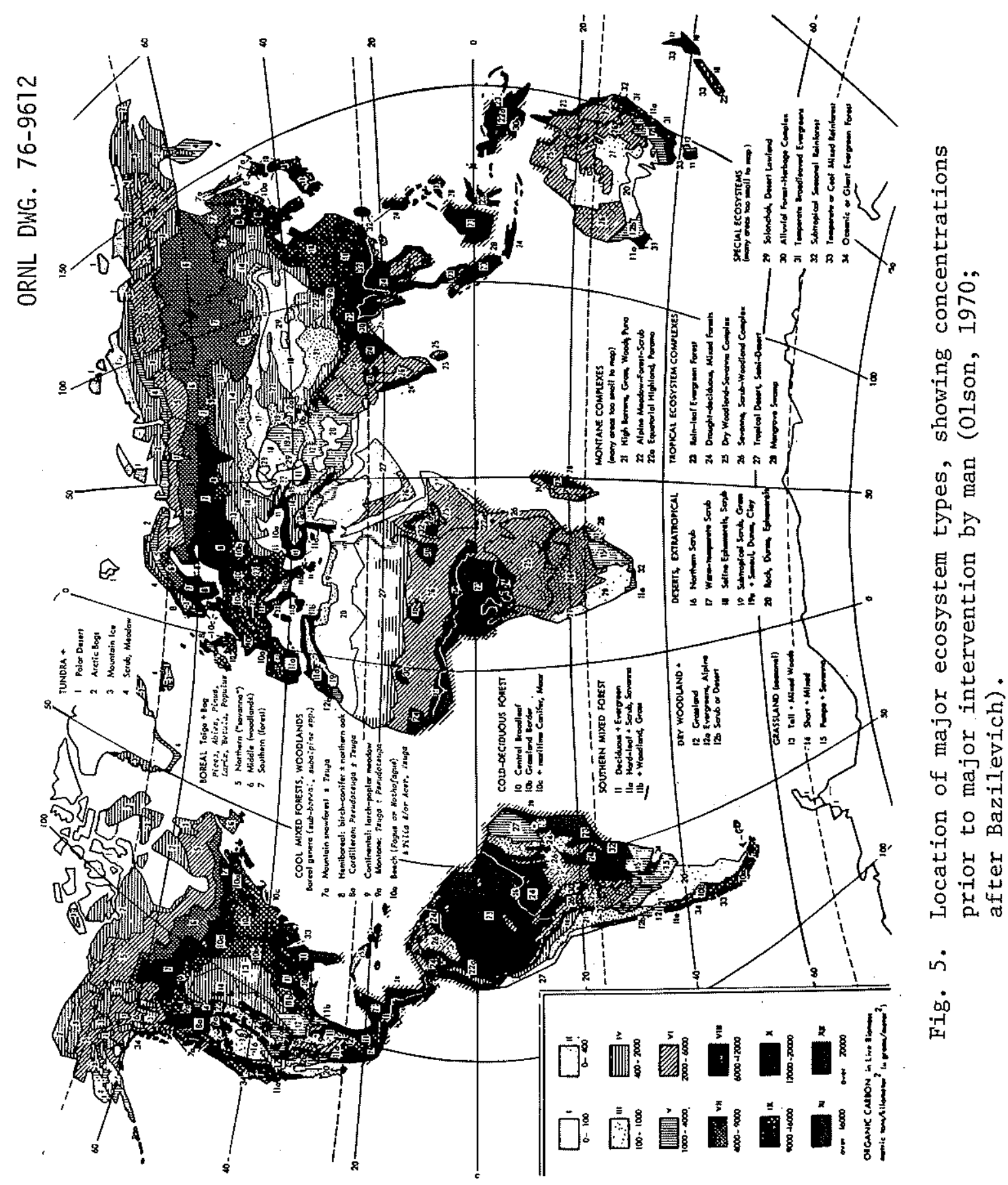


however, the thermocline weakens and the surface waters sink (or mix) to various depths and spread horizontally. This produces a worldwide circulation pattern that is quite complex and not yet adequately described. It involves descending waters mostly in polar regions and upwelling of deep water from various depths elsewhere. The approximate volumes of the three regions are:

$\begin{array}{ll}\text { Surface } & 0.024 \times 10^{9} \mathrm{~km}^{3} \\ \text { Thermocline } & 0.25 \times 10^{9} \mathrm{~km}^{3} \\ \text { Deep water } & 1.1 \times 10^{9} \mathrm{~km}^{3}\end{array}$

The most abundant forms of carbon in the ocean are inorganic, products of the reaction of $\mathrm{CO}_{2}$ and water with minerals. The principal form is bicarbonate ion $\left(\mathrm{HCO}_{3}{ }^{-}\right)$, about $89 \%$ of the inorganic carbon; about $10 \%$ is carbonate ion $\left(\mathrm{CO}_{3}=\right.$ ) and about $1 \%$ is "carbonic acid" (i.e., dissolved $\mathrm{CO}_{2}$ plus $\left.\mathrm{H}_{2} \mathrm{CO}_{3}\right)$. The total concentration of inorganic carbon is $2.0 \pm 0.1$ mmol/l in the surface waters and $2.4 \pm 0.2 \mathrm{mmol} / \mathrm{l}$ in the deep waters (Broecker and Li, 1970; Burling, 1976). The total amount of inorganic carbon in the wel1-mixed surface waters ( $580 \times 10^{9}$ tons) is close to that of the atmosphere. The total amount in the entire ocean reservoir is $39,000 \times 10^{9}$ tons, or about 56 times the atmospheric content.

The next most important form of carbon is dead organic matter, which appears to exist in a continuum of particle sizes down to small organic molecules. The concentration, which is quite variable and depends on many factors, generally falls in the range 0.04 to $0.25 \mathrm{mmol} \mathrm{C} / \ell$ (Wangersky, 1972). Taking an average value of $0.1 \mathrm{mmol} \mathrm{c} / \ell$, we obtain $\sim 29 \times 10^{9}$ tons for the surface region, about $1650 \times 10^{9}$ tons for all the oceans. Because of the variability of the concentration, both estimates are quite uncertain, the latter more so than the former.

The concentration of photosynthesizing organisms (mostly the phytoplankton) has been estimated at about $1 \mathrm{~g}$ carbon per $\mathrm{m}^{2}$ of ocean surface (Strickland, 1965), giving the content of the world oceans as $\sim 0.36 \times 10^{9}$ tons, confined to the surface region. The amount of carbon present as zooplankton and as larger animal forms is much smaller still. Whittaker (1975) and others who made better allowance for the more productive areas of coastal ocean, reefs, and upwellings--estimate almost $2 \times 10^{9}$ tons of carbon in the total living marine biomass. For this report, a number of 
the order of $1 \times 10^{9}$ seems a conservative total for the whole ocean.

Finally, another region of the ocean reservoir to be considered is the carbonate solids (formed by sea organisms), both suspended and in the surface of sediment deposits. This material is largely $\mathrm{CaCO}_{3}$ and, as we shall see, is produced in surface waters and redissolved in deep water. The deposits are generally confined to ocean depths less than $4 \mathrm{~km}$. The top $10 \mathrm{~cm}$ or so of these deposits is mixed sufficiently by the foraging activities of bottom animals that it may reasonably be included as a reactive part of the ocean system. Broecker (private communication) estimates the amount of carbon present as $\mathrm{CaCO}_{3}$ in these mobile deposits at about $410 \times 10^{9}$ tons. The deeper sediments, which contain an amount of carbon ( $3 \times 10^{16}$ tons) that dwarfs the carbon content of the oceans, cannot react at an appreciable rate with the ocean and atmosphere.

\subsection{Circulation of Carbon}

\subsubsection{Anthropogenic Fluxes}

The largest anthropogenic flux of carbon dioxide stems from man's use of fossil fuels. A careful and detailed calculative procedure was developed and reported by Keeling (1973a). This procedure was based on United Nations statistics reported in the "J Series," World Energy Supplies for the period since 1949 and on data from World Energy Requirements in 1975 and 2000 (United Nations, 1955, 1975) for years from 1860 to 1949 . It should be noted that these results also included carbon dioxide produced in the manufacture of cement for all years 1949 and after. (Cement manufacture adds less than 2 percent to the total.)

Rotty (1973) added estimates of global flaring of natural gas, and using United Nations revised fuel statistics for the period 1950 through 1974, Rotty (1976) recalculated and extended the results of Keeling. Figure 6 shows the annual $\mathrm{CO}_{2}$ production estimates from 1860 through 1974 . Evident in the figure is the slowing of global industrial growth during the periods of the world wars and the great depression of the early nineteenthirties. To the casual observer the two shorter straight line segments in the 1920's and 1930's appear to be forced. However, if only the data for 1919 through 1929 are considered, a line similar to that shown is reasonable, and similarly for the period 1932 through 1941 . It is remark- 

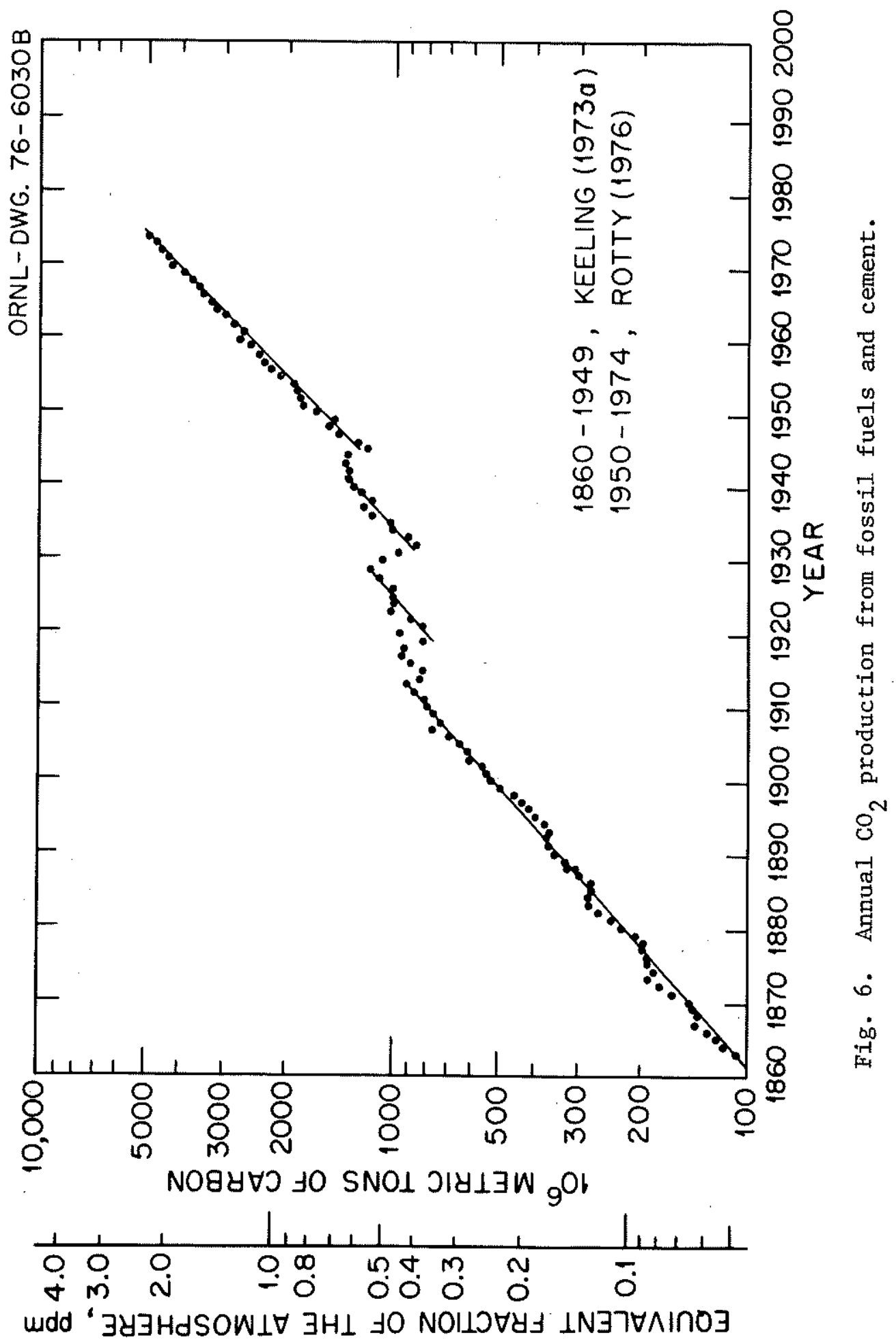
able that the slope of the line fitting the points has remained nearly constant before and after the interruptions. How long can the annual production of carbon dioxide from fossil fuels continue to grow at 4.3 percent?

The cumulative amount of $\mathrm{CO}_{2}$ produced from fossil fuels and cement is presented in Figure 7. The upper set of points indicate the increase in the carbon dioxide fraction of the atmosphere which would have occurred if all the $\mathrm{CO}_{2}$ produced since 1860 from fossil fuels and cement remained airborne. The lower set of points represents the observed increase (see Section 2.2.1) based on an assumed value of $295 \mathrm{ppm}$ in 1860 . The difference between the two sets of data indicates the amount of $\mathrm{CO}_{2}$ which is being taken up from the atmosphere by the sum of all other fluxes and stored in the oceans and possibly in terrestrial organic material.

\subsubsection{Terrestrial Ecosystem Fluxes}

The fluxes through each pool of terrestrial organic matter, as well as the pool sizes, now appear to be larger than most earlier estimates. The "production/year" from Table 2.A.1 of SCEP (1970, p. 161), is allocated to slow and rapidly exchanging pools in Table 1 and in Figure 1 of the present review.

But these only address net primary production, defined as follows:

$\mathrm{NPP}=$ photosynthetic income - respiration of green plants' parts

$$
=G P P-R_{g}
$$

The ratio of gross primary production by photosynthesis (GPP) to net primary production (NPP) generally increases from below 2 in cool climates to above 2 in warm climates. Estimates for GPP, and $R_{g}$ given in Table 1 , illustrate the general magnitude, but need to be improved both by more widely representative measures of dark and light respiration, and by better means of applying them over wide areas. Production of $\mathrm{CO}_{2}$ by respiration of green plants themselves $\left(R_{g}\right)$ may often equal or exceed the net primary production of organic material potentially available for consumption by animals and/or decomposers. Respiration by the latter, heterotrophic organisms is labeled $R_{h}$ in Table 1 . Normally it is smaller than NPP, by at least the amounts of carbon which are burned to $\mathrm{CO}_{2}$ (plus minor $\mathrm{CO}$ ). 


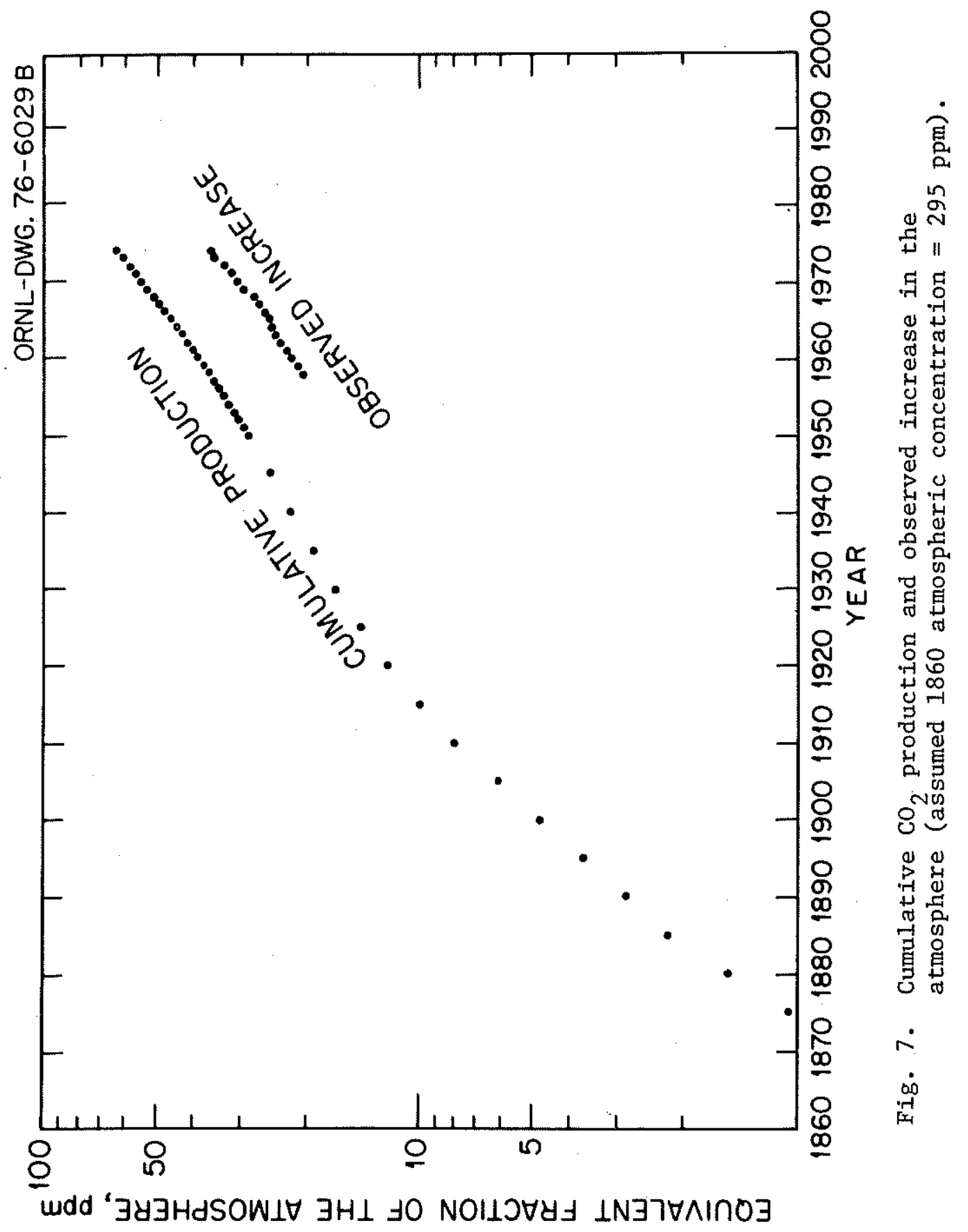




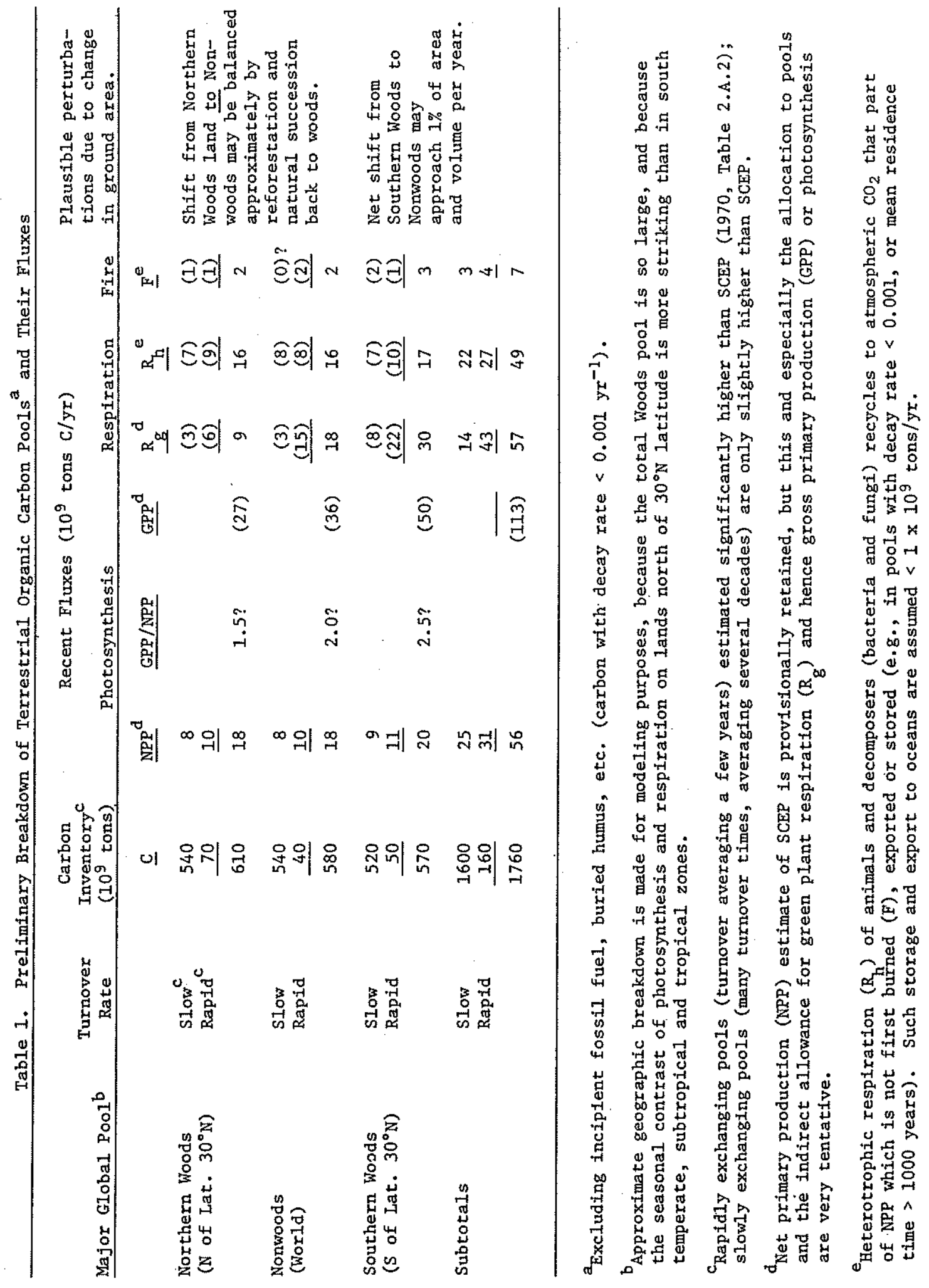


The carbon flux from fires (F) in different parts of the world also require better estimates than the rates of 2 to $3 \times 10^{9}$ tons/yr we have assigned to the Nonwoods and Woods pools in Table 1. For each Woods pool this implies a period averaging about 200 years between consuming fires in a given location. Average periods without such fires that are longer than 600 years or shorter than 100 years would seem too extreme; hence we judge these $\mathrm{F}$ fluxes from fires to be $(7 \pm 4) \times 10^{9}$ tons/yr.*

Part of the non-fuel burning has come from patchy forest clearing for slash-and-burn agriculture, extending several thousand years into prehistory but increasing rapidly under population pressures of the present century. Burning to aid grazing and hunting has had a longer past history. A lower rate of burning (perhaps $2 \times 10^{9}$ tons/yr) is conceivable in a. world without man, but even past geologic times presumably had fires from lightning-burning extensively in Woods and Nonwoods with seasonally dry climates.

We assumed that a balance exists between the total of the fluxes of Table 1 and Figure 1 into and out of each pool. Thus for a terrestrial ecosystem $^{*}$

$$
\mathrm{NPP}=\mathrm{R}_{\mathrm{h}}+\mathrm{F}
$$

The residence time $T$ is then equal to the size of the pool (C) divided by the total flux into or out of the pool

$$
\mathrm{T}=\mathrm{C} / \mathrm{NPP} \quad \text {. }
$$

For example the average residence time in the slow pool is given by $1600 / 25=64$ years. This value is an average for processes of very different rates such as tree pruning and thinning and forest product use, natural and other tree deaths (including fires), and a spectrum of residence times for different humus compounds ranging from much shorter to much longer than 64 years in their respective mean residence times.

The growing scale of man's activities requires, however, that we also

*An estimate of $13 \times 10^{9}$ tons/yr from Reiners et al., 1973, combining fire and animal respiration, but not decomposition by microorganisms, seems like an upper bound that could be exceeded only with a concerted effort to burn much more biomass as fuel (Earl, 1975; Burgess, 1975). ** We use NPP rather than GPP because turnover times of the labile material involved in $R_{g}$ are very short ( $\left.<i y r\right)$. 
consider the extent to which an imbalance may exist between the income and outgo from the various terrestrial ecosystems. Some forests have been cleared every year during the 3000 to 8000 years since Neolithic agriculture reached various parts of the world, and especially since the Iron Age. In the Northern Woods much of this change is now counteracted by reforestation, and wuch also by various natural and deflected ecological successions to woods. In Southern Woods the slash-and-burn cycle is an old traditional, energy-conserving mode of subsistence agriculture and horticulture, especially important in tropical and subtropical areas where available nutrients removed in crops and other losses are reaccumulated by forest regrowth during each cycle. Soil depletion is sometimes invoked as one factor contributing to the downfall of past civilizations (e.g., Mayan) whose population growth no longer allowed enough replenishment time during the fallow part of the cycle. Increasing application of technology and ever-greater population pressure in many developing countries are accelerating the clearing of much area called Southern Woods here.

Let us now consider the changes that could be produced if an extra $1 \%$ of the Southern Woods were permanently cleared each year to a Nonwoods condition (mostly row crops and pasture) without being balanced by equivalent areas reverting to forests as in the manner of traditional slash-andburn agriculture. Our estimates of the resulting changes are:

(1) $0.5 \times 10^{9}$ tons of Southern Woods rapid pool would disappear; $0.2 \times 10^{9}$ tons would be converted to $\mathrm{CO}_{2}$ by quick decay $\left(\mathrm{R}_{h}\right)$ and by burning (F); and $0.3 \times 10^{9}$ tons would be added to the Nonwoods rapid pool.

(2) $5.2 \times 10^{9}$ tons of Southern Woods slow pool would disappear; $1 \times 10^{9}$ tons would be burned (F), $2 \times 10^{9}$ tons would be added to the Nonwoods rapid pool, and $2.2 \times 10^{9}$ tons (mostly humus) would appear in the Nonwoods slow pool.

The prompt changes in carbon pool $\mathrm{C}$ and net primary production are summarized below:

$$
\begin{array}{cc}
\Delta C & \Delta \mathrm{NPP} \\
10^{9} \text { tons } & 10^{9} \text { tons } / \mathrm{yr}
\end{array}
$$

Nonwoods

$$
\begin{array}{lll}
\text { Slow } & 2.2 & 0.08 \\
\text { Rapid } & 2.3 & 0.12
\end{array}
$$


Southern Woods

$\begin{array}{lcc}\text { Slow } & -5.2 & -0.09 \\ \text { Rapid } & -0.5 & -0.11 \\ \text { Change } & -1.2 & 0.0\end{array}$

The immediate result is a transfer of about $1.2 \times 10^{9}$ tons/yr of organic carbon out of the organic pools and into the atmosphere (an addition almost $1 / 4$ of that currently provided by fossil fuel burning). Net primary production may not remain the same on average as assumed here. We expect the temporary or local increases due to agricultural investment may be more than offset by the replacement of many-layered photosynthetic structures, naturally adapted to diverse local habitats, by single-layered crop species, occupying the ground (and using available solar energy and $\mathrm{CO}_{2}$ ) for a smaller fraction of the year.

This example serves to illustrate that changing patterns of land use by man, in particular deforestation of Southern Woods, could appreciably increase the amount of $\mathrm{CO}_{2}$ entering the atmosphere. If future population pressures cause continued net deforestation, the perturbation on the carbon cycle could become worldwide, and the effect on the growth in atmospheric $\mathrm{CO}_{2}$ could be appreciable (see Section 2.4).

Many plant physiological studies indicate that gross and net primary production of organic carbon by photosynthesis can increase with increasing atmospheric $\mathrm{CO}_{2}$. The common practice since the SCEP (1970) analysis has been to assign a factor $\beta<1$ to describe the proportional increase, since unfavorable factors like drought, nutrient deficiency and cold would prevent $\beta$ from approaching 1 . Oeschger et al., (1975) found values of $\beta$ from 0 to 0.4 to be consistent with acceptable parameters in their boxdiffusion model of the oceans (see next section). Keeling's (1976) models seem most plausible if $\beta$ (as applied to NPP) $=0.27$. Using this factor, atmospheric $\mathrm{CO}_{2}$ increase during the past century should have caused NPP to increase by the factor $0.27 \times(330-295) / 295=0.032$. Multiplying by an NPP estimate of $56 \times 10^{9}$ tons/yr suggests an additional removal of about $1.8 \times 10^{9}$ tons of carbon per year current1y from the atmosphere compared with preindustrial levels. The number could well be twice as high if such a value of $\beta$ were applicable to GPP $\left(\sim 113 \times 10^{9}\right.$ tons/yr) instead of NPP. In conclusion, enhanced photosynthesis rates might exceed the incre- 
ment $C$ of carbon immediately released to the atmosphere by fire from accelerated land clearing. Even so the slightly delayed releases of additional $\mathrm{CO}_{2}$ from accelerated turnover of the urburned organic matter during tropical land clearing probably exceed the capacity of the remaining Woods and Nonwoods to $\mathrm{fix} \mathrm{CO}_{2}$ at an accelerated rate. Predictions of the future shifting balance (or rather imbalance) of these opposing tendencies will require the formulation and testing of models including all of the factors introduced in this review. Aspects which we have assumed to be of secondary importance (freshwater ecosystems, deposition and oxidation of peat, roles of main animal groups, and man's durable and other comodities and wastes) should also be reconsidered in more complete models.

\subsubsection{Ocean Fluxes}

In the presence of water, $\mathrm{CO}_{2}$ "weathers" limestone $\left(\mathrm{CaCO}_{3}\right)$ to form soluble calcium bicarbonate by the reaction,

$$
\mathrm{CaCO}_{3}(\mathrm{~s})+\mathrm{CO}_{2}(\mathrm{~g})+\mathrm{H}_{2} \mathrm{O}=\mathrm{Ca}^{++}+2 \mathrm{HCO}_{3}{ }^{-} \text {. }
$$

The effect of weathering thus is to transport $\mathrm{CaCO}_{3}$ from the continents to the ocean along with an equivalent amount of $\mathrm{CO}_{2}$. The flux involved, judging from the total river flow of the world, is about $0.38 \times 10^{9}$ tons of carbon per year (Mackenzie and Garrels, 1966). Other weathering processes such as the reactions of sulfuric acid (from $\mathrm{SO}_{2}$ oxidation) with limestone, and the oxidation of exposed deposits of coal, shale, and peat add to the flux of carbon in the rivers, but the total will no doubt remain small compared to other fluxes.

As Sillén (1963), Holland (1972), and others have pointed out, in the long run, the composition of the oceans is probably controlled within rather narrow limits by reversible chemical reactions involving various minerals in the ocean sediments. Among these is $\mathrm{CaCO}_{3}$ and, on the average, the sea waters of the world are close to saturated with it, as defined by reaction (4) above. Consequently, the atmospheric partial pressure of $\mathrm{CO}_{2}$ is related to the ion concentration product of calcium bicarbonate in accordance with the equilibrium condition

$$
\mathrm{K}_{1}=\left[\mathrm{Ca}^{++}\right]\left[\mathrm{HCO}_{3}{ }^{-}\right]^{2} / \mathrm{P}_{\mathrm{CO}_{2}} .
$$


$\mathrm{K}_{1}$ is a constant for $\mathrm{CaCO}_{3}$-saturated solutions that depends on the temperature and pressure. ${ }^{*}$ Since the total amount of calcium and bicarbonate ions in the oceans and the amount of $\mathrm{CaCO}_{3}$ in marine sediments is large compared to that in the atmosphere, this constraint alone could be sufficient to hold the $\mathrm{CO}_{2}$ content of the atmosphere within fairly narrow limits if the fluxes of the reacting species within the oceans were large enough. Indeed the magnitude of the various fluxes of $\mathrm{CO}_{2}$ and its reaction products in the ocean may ultimately determine the limits of $\mathrm{CO}_{2}$ concentration in the atmosphere.

The rate of exchange of atmospheric $\mathrm{CO}_{2}$ with surface water has been estimated from ${ }^{14} \mathrm{C}$ data (reviewed by Keeling, $1973 \mathrm{~b}$ and Oeschger, et a1., 1975 ) to be equivalent to about $13 \%$ of the atmospheric reservoir and $15 \%$ of the reservoir in the surface water per year. This gives a flux in either direction of about $90 \times 10^{9}$ tons of carbon per year, about twice the photosynthesis rate (see below). The reservoir of carbon in the surface water thus can respond fairly rapidly (in a few years) to the increasing atmospheric concentration of $\mathrm{CO}_{2}$.

The capacity of this reservoir to respond is limited, however, because the most important reaction responsible for the takeup of $\mathrm{CO}_{2}$ by the oceans is

$$
\mathrm{CO}_{2}(\mathrm{~g})+\mathrm{CO}_{3}=+\mathrm{H}_{2} \mathrm{O} \stackrel{\leftarrow}{\lessgtr} 2 \mathrm{HCO}_{3}^{-}
$$

and the supply of $\mathrm{CO}_{3}{ }^{=}$is limited (about $13 \%$ of the inorganic carbon present). The other reactions of $\mathrm{CO}_{2}$ that can occur in the surface water are not very important either because the equilibrium is unfavorable or the extent of reaction is constrained by the requirement that the total of the charges on all anions and cations remain balanced.

To explore more quantitatively the consequences of this situation, we will first make the approximation that reaction (5) above is the only one that occurs, i.e., that $\mathrm{CO}_{3}{ }^{2}$ and $\mathrm{HCO}_{3}{ }^{-}$are the only species of carbon present in the oceans. The equilibrium constant for reaction (5) is

$$
\mathrm{K}_{2}=\frac{\left[\mathrm{HCO}_{3}^{-}\right]^{2}}{\mathrm{P}_{\mathrm{CO}_{2}}\left[\mathrm{CO}_{3}=\right]}
$$

From this expression it may be seen that a fractional increase in $\mathrm{P}_{\mathrm{CO}_{2}}$ ${ }^{*} \mathrm{~K}_{1}$ is also affected slightly by the small variations in the salinity of sea
water. 
will produce at equilibrium an equal fractional increase in the factor $\left[\mathrm{HCO}_{3}{ }^{-}\right]^{2} /\left[\mathrm{CO}_{3}{ }^{-}\right]$. The fractional increase in the total inorganic carbon content that results is much smaller, however, because of the small proportion present as $\mathrm{CO}_{3}{ }^{2}$. The ratio of fractional changes in the atmosphere and the surface water

$$
\mathrm{B}=\mathrm{d} \ln \mathrm{P}_{\mathrm{CO}_{2}} / \mathrm{d} \ln \sum \mathrm{C},
$$

is given by differentiation of Equation 6 as

$$
B=\frac{1+3 R}{R(1-R)},
$$

where

$$
\mathrm{R}=\left[\mathrm{CO}_{3}{ }^{=}\right] / \mathrm{LC}
$$

and

$$
\Sigma \mathrm{C}=\left[\mathrm{CO}_{3}{ }^{-}\right]+\left[\mathrm{HCO}_{3}{ }^{-}\right]
$$

Thus we see that if reaction (5) were the only one occurring, the ratio $B$ of fractional changes in the atmosphere and in the sea at equilibrium would depend only on $R$, the fraction of the total inorganic carbon that is $\mathrm{CO}_{3}{ }^{2}$. Since $\mathrm{R}$ is fairly small, the resulting value of $\mathrm{B}$ (called the buffer factor) is fairly large. (The average value of $\mathrm{R}$ for surface water is $\approx 0.13$, from which Equation 8 gives $B=12.3$. ) This means that the fractional increase of carbon in surface water will be much less than that in the atmosphere. Moreover, as the limited supply of $\mathrm{CO}_{3}=$ ion in the surface water is consumed, $R$ decreases and the buffer factor increases.

The accurate calculation of the buffer factor (described by Keeling, 1973b) includes contributions from the minor neutral species of dissolved $\mathrm{CO}_{2}$ [i.e., $\mathrm{CO}_{2}(\mathrm{aq})$ and $\mathrm{H}_{2} \mathrm{CO}_{3}$ ] and changes in the concentration of minor ions [such as $\mathrm{B}(\mathrm{OH})_{4}^{-}$and $\mathrm{OH}^{-}$], the latter being constrained by the requirement that the balance of charges be preserved. These contributions lower the buffer factor. Keeling gives values of $\mathrm{B}$, now including $\mathrm{CO}_{2}(\mathrm{aq})$ and $\mathrm{H}_{2} \mathrm{CO}_{3}$ in $\mathrm{\Sigma} \mathrm{C}$ (Eqs. 7 and 10 above), near 9. Another point to be noted is that the buffer factor is often defined in terms of the pre-industrial values $\mathrm{P}_{\mathrm{CO}_{2}}{ }^{\circ}$ and $\Sigma \mathrm{C}^{\circ}$

$$
\left[\frac{{ }^{\mathrm{dP}} \mathrm{CO}_{2}}{\mathrm{~d} \Sigma \mathrm{C}} / \frac{{ }_{\mathrm{CO}_{2}}{ }^{\circ}}{\Sigma \mathrm{C}^{\circ}}=\mathrm{B} \cdot \frac{{ }_{\mathrm{CO}_{2}}}{\mathrm{P}_{\mathrm{CO}_{2}}{ }^{\circ}} \cdot \frac{\Sigma \mathrm{C}^{\circ}}{\Sigma \mathrm{C}}\right]
$$


This factor, on the left above, is called the Revelle factor and it increases with time more rapidly than B (Keeling, 1973, p. 286). While an accurate calculation of the buffer factor is fairly involved, the main point to be noted is that it depends most strongly on the fraction $\left[\mathrm{CO}_{3}{ }^{3}\right] / \Sigma \mathrm{C}$, reflecting the fact that the limited supply of $\mathrm{CO}_{3}=$ limits the capacity of surface water to respond to changes in atmospheric $\mathrm{CO}_{2}$.

This estimate of the capacity of surface waters to take up $\mathrm{CO}_{2}$ does not include the effect of the circulation between and mixing of deep waters and surface waters. From the distribution in the ocean of ${ }^{14} \mathrm{C}$, which originates in the atmosphere, it has been estimated from box models that the residence time of water in the deep ocean is in the range 500 to 2000 years (Broecker and Li, 1970; Oeschger et al., 1975). This would suggest a circulation of 0.5 to $2 \times 10^{6} \mathrm{~km}^{3}$ per year, or only 2 to $8 \%$ of the volume of surface water per year. Hence box models suggest that deep circulation should not greatly increase the capacity of the ocean to respond to relatively rapid increases in atmospheric $\mathrm{CO}_{2}$. Oeschger et a1., (1975) point out, however, that if mixing of the surface water with deep water occurs by eddy diffusion, with a diffusion coefficient of $\sim 4000 \mathrm{~m}^{2} / \mathrm{yr}$ (about $10^{5}$ fold larger than molecular diffusion coefficients), then the capacity of the oceans to take up $\mathrm{CO}_{2}$ is sufficient to account for the observed loss of $\mathrm{CO}_{2}$ from the atmosphere, a loss which is equivalent to $\sim 50 \%$ of the anthropogenic flux. This treatment also accounts reasonably well for the observed distribution of ${ }^{14} \mathrm{C}$ in the ocean.

The diffusion model yields fluxes of $\mathrm{CO}_{2}$ to the deep oceans several fold larger than those given by simple box models because the concentration of $\mathrm{CO}_{2}$ in the atmosphere changes rapid1y compared to the residence times of carbon in the deep ocean. The assumption of downward diffusion from the surface waters leads to the growth of a concentration gradient that can store large amounts of inorganic carbon and sustain a higher flux. In the simple box models the deep ocean is considered to be well mixed and homogeneous. As a result its capacity to take up $\mathrm{CO}_{2}$ is limited by a flux from surface water which must remain small to be consistent with the great ${ }^{14} \mathrm{C}$ age of the deeper ocean. *

* Keeling (1973b, p. 257) discusses box models in which the deep ocean is not well mixed. 
The model of Oeschger et al., (1975) while apparently the most successful to date in accounting for ${ }^{14} \mathrm{C}$ data and the apparent takeup of $\mathrm{CO}_{2}$ by the oceans, does not include what is known of the details of circulation between surface water and deep water (Bolin, 1975). The circulation of the oceans has been described graphically by Broecker (1974). The cold surface water is depleted somewhat in $\mathrm{HCO}_{3}{ }^{-}$but rich in $\mathrm{CO}_{3}{ }^{2}$, and thus supersaturated with $\mathrm{CaCO}_{3}$, as a result of biological activity which consumes $\mathrm{CO}_{2}$ and shifts reaction (5) to the left. The average concentrations are

$$
\left[\mathrm{HCO}_{3}{ }^{-}\right]=0.00195 \text { moles } / \ell ;\left[\mathrm{CO}_{3}{ }^{-}\right]=0.00020 \mathrm{moles} / \ell
$$

This water takes up $\mathrm{CO}_{2}$ from the atmosphere and descends, largely in the Arctic Ocean and Norwegian Sea, it traverses the deep Atlantic and Indian Oceans, and finally reaches the Pacific Ocean. All along the way, portions of deep water rise by eddy diffusion through the thermocline and by localized upwelling.

Respiration and decay processes produce $\mathrm{CO}_{2}$ and with increasing depth shift reaction (5) to the right, causing the $\mathrm{CO}_{3}=$ concentration to decrease and the $\mathrm{HCO}_{3}{ }^{-}$concentration to increase. As a result water of intermediate depth is approximately saturated with $\mathrm{CaCO}_{3}$ and deeper water is unsaturated. The resulting average concentrations in deep water are

$$
\left[\mathrm{HCO}_{3}{ }^{-}\right]=0.00235 \mathrm{moles} / \ell ;\left[\mathrm{CO}_{3}{ }^{=}\right]=0.00010 \mathrm{moles} / \ell \text {. }
$$

As deep water upwells it delivers $\mathrm{CO}_{2}$ to the atmosphere and fresh nutrients to the surface waters, including the bio-limiting ones, phosphorus and silicon.

From estimates of the rate of upwelling, Broecker (1974, p. 63) finds that for a steady state to prevail about $1.7 \times 10^{9}$ tons $\mathrm{C} / \mathrm{yr}$ of organic debris must descend from the surface water, accompanied by half as much $\mathrm{CaCO}_{3}$-containing material. Only a small fraction of this material reaches the bottom sediments.

Estimates of marine productivity (GPP and NPP) are much higher than the rates at which debris leave the surface waters, indicating that limiting nutrients are recycled many times between plant and animal forms before they return to the depths. Marine productivity estimates by Ryther (1969) of $20 \times 10^{9}$ tons per year and by Koblentz-Mishke et a1., (1970) of 
$23 \times 10^{9}$ tons per year are considered by Bunt (1975) and others to "need revision upward"--especially if total photosynthesis or gross primary production is desired. Here we adopt the latter number as the net primary production estimate (NPP), but this may require further revision for seaweed and bottom or benthic production in the near coastal belt of shallow ocean, which is fertilized by nutrients from land (Woodwell, et a1., 1973). Estimating twice $23 \times 10^{9}$ or $46 \times 10^{9}$ tons per year for gross photosynthesis (GPP) probably makes adequate allowance for plant respiration plus excretion and organisms which are missed or underestimated by the typical radiocarbon uptake measurements on which the numbers first cited were based. Both gross and net production may be an order of magnitude lower than average in the central ocean areas where the thermocline barrier to nutrient upwelling is especially strong, and may be an order of magnitude higher in areas of strongest upwelling and in certain coastal areas where nutrients are contributed from streams and coastal marshes.

Returning to the response of the ocean to increasing atmospheric $\mathrm{CO}_{2}$, increased injections of $\mathrm{CO}_{2}$ into the cold descending surface water will reduce the $\mathrm{CO}_{3}=$ in the deep water. As a result, more $\mathrm{CaCO}_{3}$ will dissolve (eq. 4) from both the descending $\mathrm{CaCO}_{3}$ and the mobile surface of the sediments. The boundary between deep $\mathrm{CaCO}_{3}$-unsaturated waters and the less deep saturated waters will rise. The rate of production of $\mathrm{CaCO}_{3}$ will, as a first approximation, not change. The net result would be consumption of a portion of the increased atmospheric $\mathrm{CO}_{2}$ and an equivalent decrease in the amount of descending and deposited $\mathrm{CaCO}_{3}$.

The ultimate capacity of the oceans to consume anthropogenic $\mathrm{CO}_{2}$ is probably in excess of what is needed because of the large amounts of accumulated $\mathrm{CaCO}_{3}$ which could be made available for reaction through the deep water circulation and the activities of foraging bottom animals. However, the important point is that this response is probably much too slow (i.e., requiring hundreds of years) to prevent a major increase in the atmospheric concentration.

\subsection{Predicting Future Levels of $\mathrm{CO}_{2}$}

As noted in Section 2.3.1, the addition of carbon dioxide to the atmosphere from the burning of fossil fuel and the manufacture of cement 
has, except for occasional interruptions, been increasing at an annual rate of $\sim 4.3 \%$ for over 100 years. The amount of $\mathrm{CO}_{2}$ added to the atmosphere in 1974 was nearly $5 \times 10^{9}$ tons of carbon. The parallel curves in Figure 7, which compare the resulting cumulative production of anthropogenic $\mathrm{CO}_{2}$ with the increasing amount of atmospheric $\mathrm{CO}_{2}$ in excess of the pre-industrial value ( $295 \mathrm{ppm}$ ), reveal that the anthropogenic flux has been partially balanced by nearly constant fractional losses to oceanic and/or terrestrial pools. The present $\mathrm{CO}_{2}$ content of the atmosphere ( $330 \mathrm{ppm}$ by volume) is about $12 \%$ higher than the pre-industrial value.

Based on a continued annual growth rate of fossil fuel usage of $4.3 \%$ per year, by the year 2000 the annual global production of $\mathrm{CO}_{2}$ from this source will reach $14.3 \times 10^{9}$ tons, and by 2025 it will reach $42 \times 10^{9}$ tons. The burning of fossil fuel at this rate will result in a total amount of $\mathrm{CO}_{2}$ from fossil fuel to the atmosphere equivalent to increases of $169 \mathrm{ppm}$ by 2000 and $478 \mathrm{ppm}$ by 2025 (totals of production, 1860-2000 and 1860-2025). If half of this fossil fuel flux is passed on to the oceans and the terrestrial biosphere, then the atmospheric concentration of $\mathrm{CO}_{2}$ will be around $380 \mathrm{ppm}$ in 2000 and $534 \mathrm{ppm}$ in 2025 . While the burning of fossil fuel at this rate probably provides an uppex limit on the flux to the atmosphere from this source, the atmospheric concentrations suggested here are not upper limits, because they are based on the assumption of $50 \%$ of the amount produced remaining airborne. Many investigators believe that the net fraction remaining in the atmosphere will increase as the buffer factor of the ocean increases (Keeling, 1976), and the large forests are cleared (01son, 1976).

The increase of $\mathrm{CO}_{2}$ production becomes most striking early in the twenty-first century. An on-going, but as yet unpublished, study at IEA (1976) shows that for a wide variety of future energy scenarios, including both wide acceptance of nuclear power on a global scale as well as its non-acceptance, the cumulative $\mathrm{CO}_{2}$ production is doubled or more in every case between $\mathrm{AD} 2000$ and $\mathrm{AD}$ 2025. Projections published by Rotty (1976) do not go beyond $A D 2000$, but an extension from that date shows that a doubling of fossil fuel use between 2000 and 2025 (a mere $2.8 \%$ annual growth rate) would release about $125 \%$ as much $\mathrm{CO}_{2}$ during this 25 year period as will have been released during the entire 140 year period from 1860 to 2000 . 
Based on data developed by USGS for global coal reserves (Averitt, 1975) and by Hubbert (1974) for liquid and gas fuel reserves, we estimate the ultimate release of carbon from burning fossil fuels could reach $5.6 \times 10^{12}$ tons. Adding an estimated $1.7 \times 10^{12}$ tons of $\mathrm{C}$ from oil shale containing 25 gal per ton or more (Duncan and Swanson, 1965), the total potential release is 1 ikely to be $7.3 \times 10^{12}$ tons of carbon. The continued exponential growth scenario to 2025 suggested above releases a total of (1860-2024) $10^{12}$ tons of carbon - about $1 / 7$ of that available. There clearly is a sufficient supply of fossil fuel to satisfy all the scenarios and to give significant increases in atmospheric $\mathrm{CO}_{2}$ concentration. Assumed continued burning of fossil fuels for a major portion of the global energy supply after 2025 and through the middle decades of the twenty-first century will drive the atmospheric concentration well above twice the preindustrial level. If all the remaining recoverable fossil fuel (including probable economic oil from shale) is burned at a rate slow enough that half of the $\mathrm{CO}_{2}$ released can be exchanged with other reservoirs (oceans and the land biota), then this burning will result in the atmospheric concentration rising to 6.9 times the 1860 concentration.

Keeling (1976) has constructed a model to predict atmospheric $\mathrm{CO}_{2}$ levels farther into the future (Figs. 8 and 9). His function for $\mathrm{CO}_{2}$ production from fossil fuel assumes an exponential growth multiplied by a depletion factor raised to the power $\alpha$. The rate at which $\mathrm{CO}_{2}$ leaves the atmosphere and the amount present at a given time is calculated by means of a six-box model. Depending on the rate of use of the remaining fossil reserves, Keeling predicts the atmospheric concentration will peak at 7 to 8 times the 1860 value between 2075 and 2275 .

Estimates of future $\mathrm{CO}_{2}$ concentrations in the atmosphere have usually been made assuming that the fossil fuel flux is partially balanced by the sum of all other fluxes to and from the atmosphere, and that the fraction being stored elsewhere remains constant. This obviously crucial assumption is made in the absence of any certain knowledge of how the other fluxes accomplish so much removal at present or how they may change in the future. For the moment, the best that can be done is to estimate the variations that are possible in the larger of the other fluxes. Terrestrial ecosystem fluxes, as has been discussed in Section 2.3.2, 


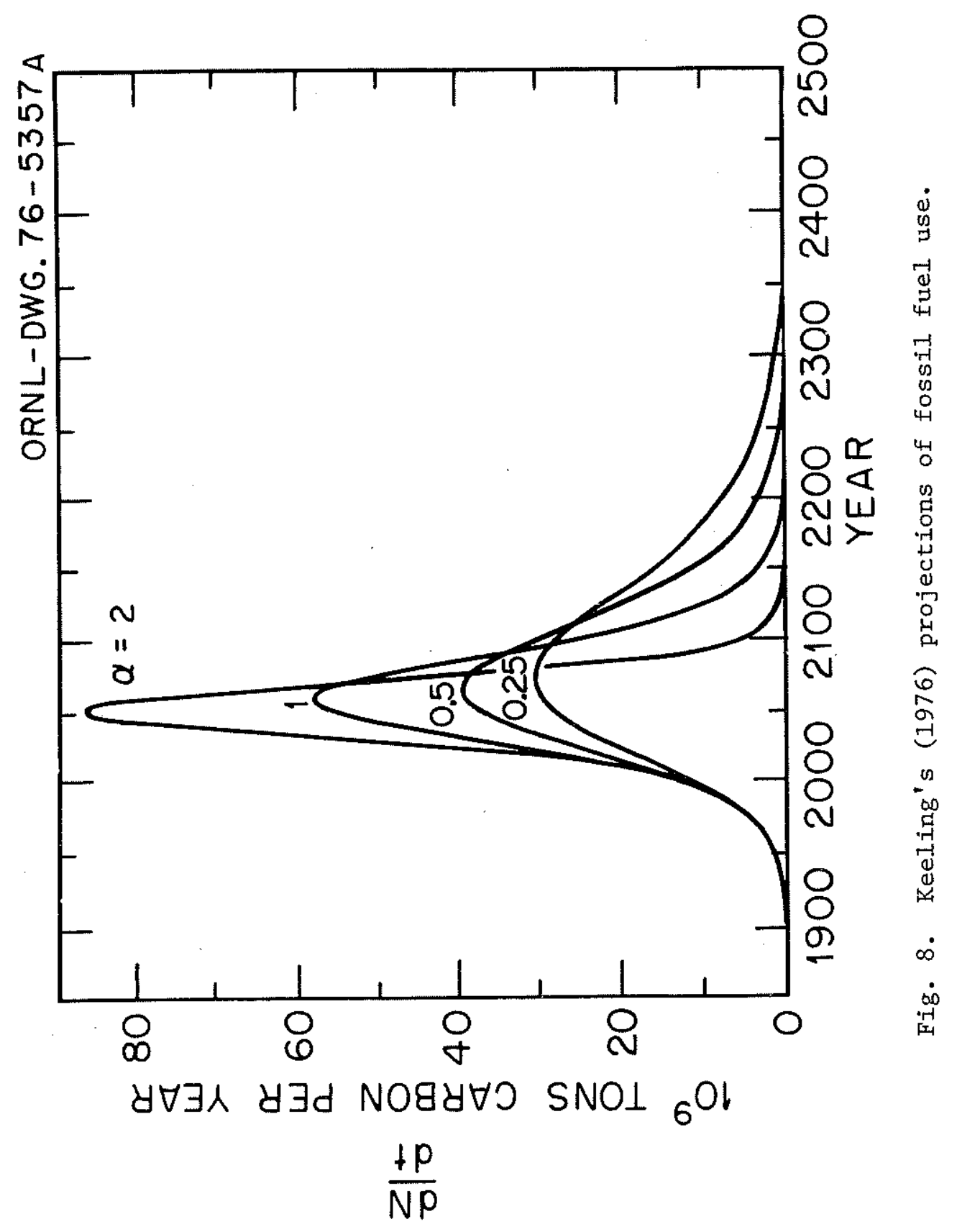




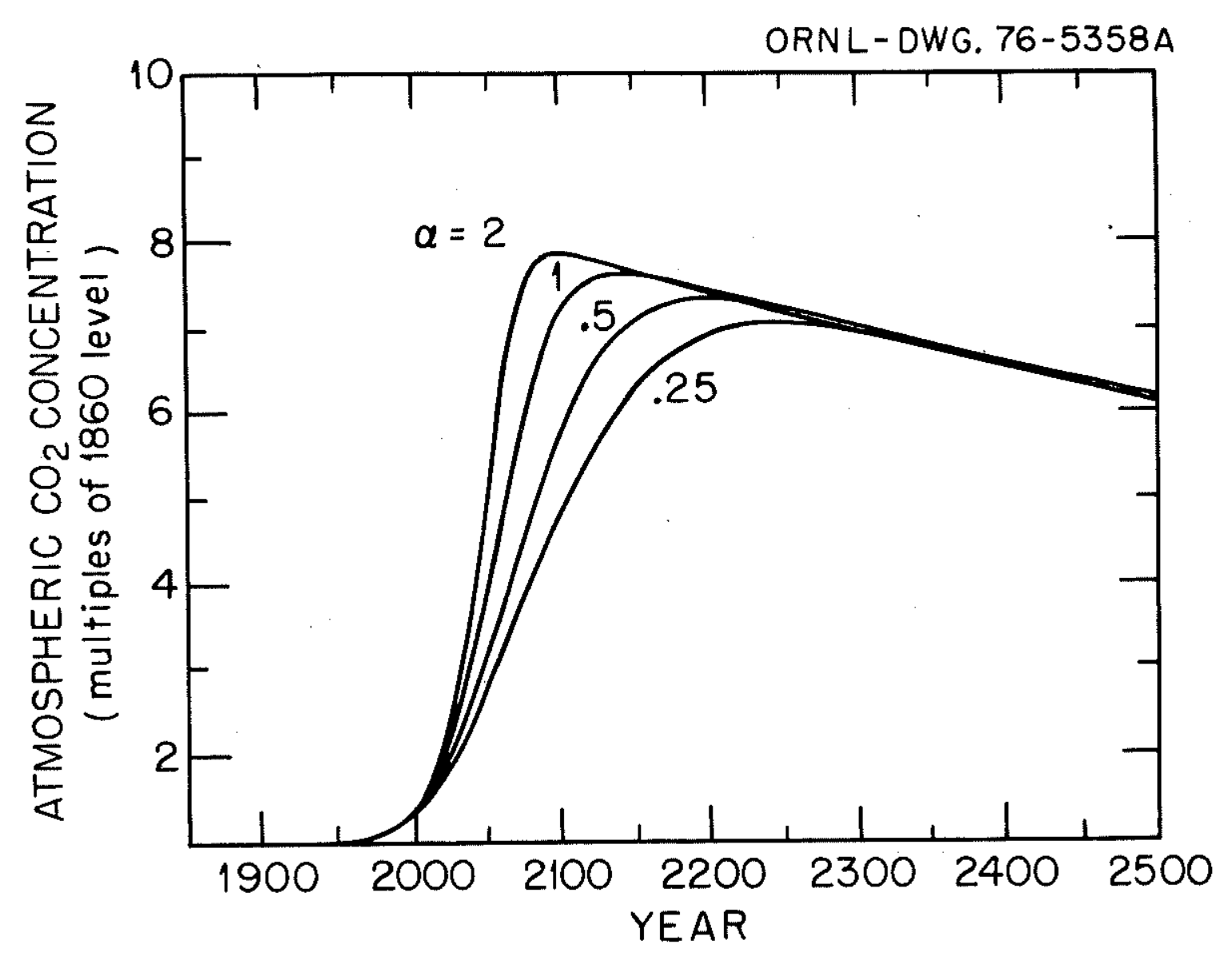

Fig. 9. Keeling's (1976) projections of atmospheric $\mathrm{CO}_{2}$ level from fossil fuel use rates in Fig. 8. 
could be changed substantially by changes in rates of burning, in patterns of land use, and in the use of biomass as fuel. The flux from fires, which may at present exceed that from the burning of fossil fuels, will be increased by an intensification of slash-and-burn agriculture and increased rates of other conversion of woods to nonwoods. Burning will also be increased if more biomass is used as fuel, though this might partly be cancelled by a decrease in the use of fossil fuel and by programmed regrowth. The net effect of these activities is likely to be an increase in the flux of $\mathrm{CO}_{2}$ from the terrestrial biota to the atmosphere, at least in the next 100 years.

Perhaps the simplest way to judge the uncertainty in predicting the net flux from the terrestrial biota is to consider the following extreme cases:

(1) Population pressure forces the conversion of all arable land to food production in 100 years, thus converting a substantial fraction of the standing crop of wood to $\mathrm{CO}_{2}$. This could amount to as much as $200 \times 10^{9}$ tons of extra carbon to the atmosphere and if it were converted at a constant rate over the next century, the flux would be $2 \times 10^{9}$ tons per year.

(2) With decreasing growth of population, more efficient agriculture, increasing use of biomass as fuel (with planned regrowth), less wasteful burning, and especially if photosynthetic productivity increases with greater atmospheric $\mathrm{CO}_{2}$ level, it is possible to imagine that a terrestrial flux of $2 \times 10^{9}$ tons per year, in the opposite direction would result.

On this basis we assign a range of $\pm 2 \times 10^{9}$ tons per year to possible changes in the net flux from the terrestrial biota to the atmosphere averaged over the next 100 years. We also note that the potential for control of the flux to the atmosphere through control of these terrestrial activities by man is substantial.

The oceans are thought by many to be the sink which accounts for the largest part of the $\sim 50 \%$ equivalent of the anthropogenic flux that leaves the atmosphere. The capacity of the surface waters to take up $\mathrm{CO}_{2}$ is so limited and the circulation to deep waters given by simple box models is so small, however, that this would seem possible only if appreciable 
diffusive mixing between deep water and surface waters is taking place. Since the net consumption of $\mathrm{CO}_{2}$ by photosynthesis in surface waters appears to be limited by the supply of nutrients (phosphorus and silicon) from the deep water, this flux should not depend on the level of $\mathrm{CO}_{2}$ in the atmosphere. Change in the net flux to the oceans thus presumably will depend primarily on changes that occur in the circulation between surface water and deep water. While the extent of such changes is not known, it is not difficult to imagine that they could be substantial. For present purposes, we will assume that the uncertainty in the net flux to the ocean will be equivalent to $\pm 10 \%$ of the fossil fuel flux.

For the purposes of this study, we now select a high fossil fuel use scenario and a low fossil fuel use scenario and project each into the future as far as 2075 . These two cases should provide an upper and a lower limit on probable future carbon dioxide production and atmospheric concentration. The high fossil fuel scenario is based on a growth rate starting at $4.3 \%$ per year but the growth rate is reduced in proportion to the fraction of the ultimate fossil fuel supply which has been used. Mathematically, this is similar to one of Keeling's (1976) projections:

$$
\frac{1}{\mathrm{~N}} \frac{\mathrm{dN}}{\mathrm{dt}}=\mathrm{R}\left(1-\frac{\mathrm{N}}{\mathrm{N}_{\infty}}\right)
$$

Where: $\mathrm{N}$ is the cumulated amount of carbon in burned fossil fuel

$R$ is the present annual growth rate $(0.043)$ $\mathrm{N}_{\infty}$ is the total carbon in recoverable fossil fuel

The low fossil fuel scenario assumes a $2 \%$ growth in fossil fuel burning until 2025 and a symmetrical decrease (phasing out) thereafter as renewable energy sources become more readily available and use of fossil fuel is discouraged. These configurations are shown in Figure 10.

The cumulative production of carbon dioxide which will result from fossil fuels is depicted graphically for both the high use and low use futures in Figure 11. This can be regarded as a continuation of Figure 7. The shaded band around each curve represents the uncertainty of $\pm 2 \times 10^{9}$ tons per year from anthropogenic changes in the terrestrial biota. Figure 12 shows the results of these growth patterns on the concentration of $\mathrm{CO}_{2}$ in the atmosphere. To reflect the uncertainty of the net 


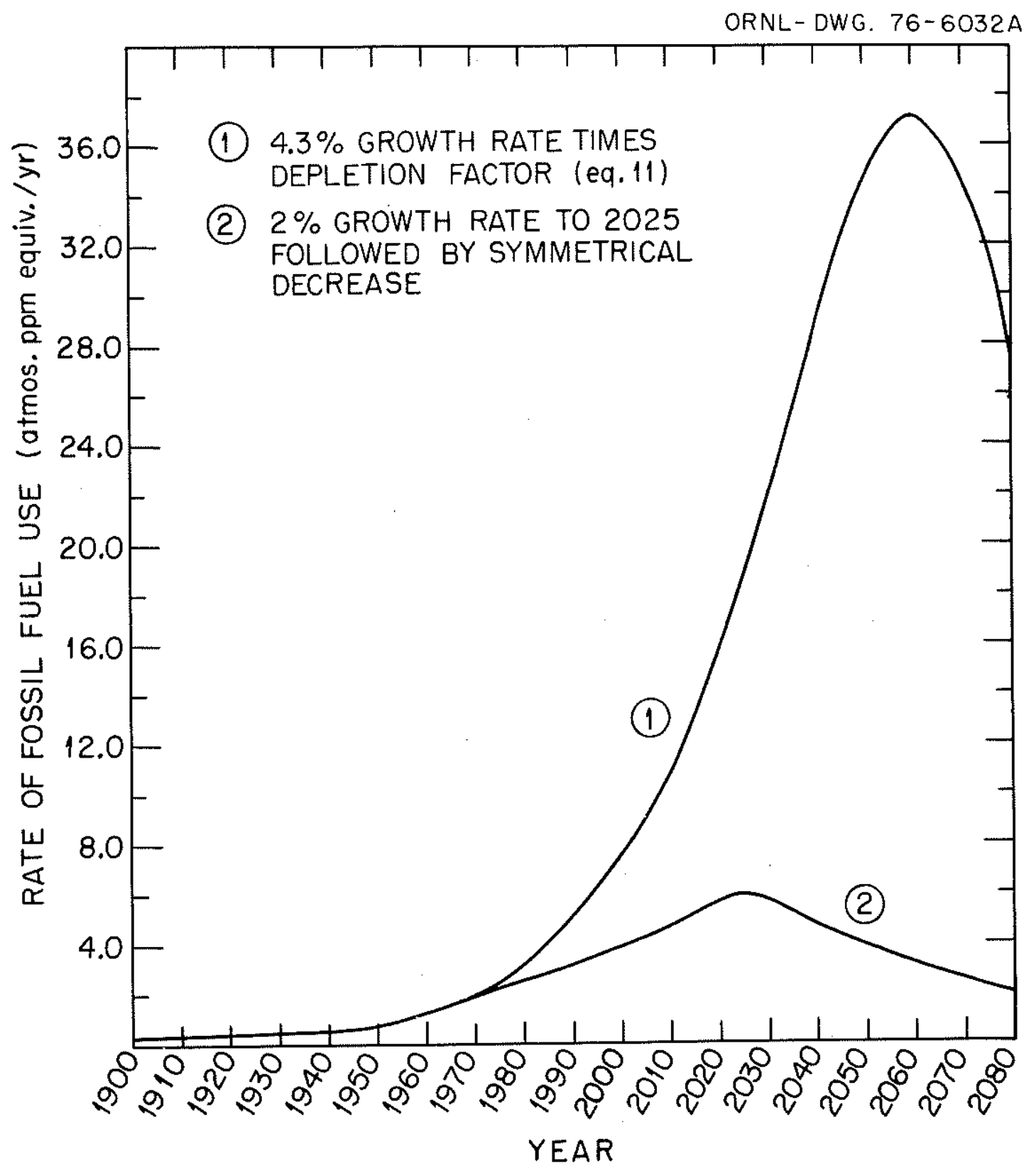

Fig. 10. Possible limiting scenarios for the use of fossil fuels. 


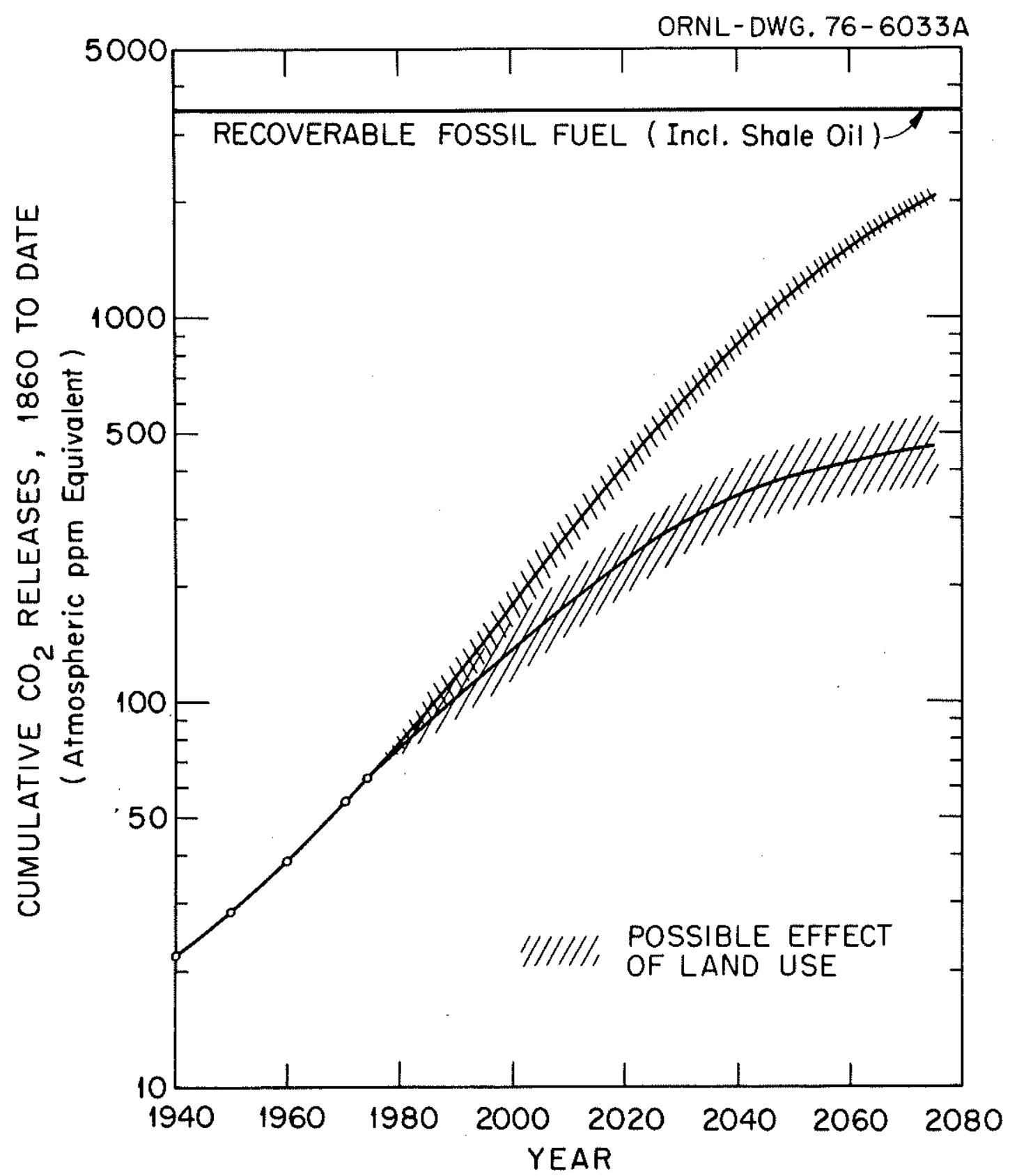

Fig. 11. Cumulative $\mathrm{CO}_{2}$ releases from limiting cases in Fig. 10. 
$\mathrm{CO}_{2}$ flux to the ocean, the bands now include the added effect of a $\pm 10 \%$ change in the equivalent fraction of the fossil-fuel flux that remains airborne.

We conclude this section by noting that it seems clear that anthropogenic additions of $\mathrm{CO}_{2}$ will substantially increase the atmospheric concentration in the coming 100 years (Fig. 12). The amount of the increase will depend primarily on the rate of consumption of fossil fuel, but appreciably on land-use patterns and on the fraction of $\mathrm{CO}_{2}$ that is stored in the oceans. Prudence dictates that mankind learn more about the fluxes of the carbon cycle, how they co-vary, and how to manipulate as beneficially as possible those fluxes that he can control.

\subsection{Atmospheric $\mathrm{CO}_{2}$ and Climate Change}

Before considering the possible climate changes caused by man's activities, it is instructive to note the long history of natural climate change that is revealed by the geologic record. In a recent review (ICAS, 1974), fluctuations of the average surface temperature over the past one million years were represented approximately by sinusoidal variations with different periodicities, giving the following results (from ICAS, 1974, Table 1):

\begin{tabular}{c}
$\begin{array}{c}\text { Characteristic } \\
\text { Period } \\
\text { (yrs) }\end{array}$ \\
\hline
\end{tabular}

100,000

20,000

2,500

$\sim 200$

$\sim 100$

\begin{tabular}{cc}
$\begin{array}{c}\text { Fluctuation } \\
\text { in Ave. Temp. } \\
\left({ }^{\circ} \mathrm{K}\right)\end{array}$ & Last Temp. \\
\hline
\end{tabular}

8.0

3.0

2.0

0.5

0.5
Max. Rate of Temp. Change

$\left({ }^{\circ} \mathrm{K} / \mathrm{yr}\right)$

$\pm 0.00025$

$\pm 0.00045$

$\pm 0.0025$

$\pm 0.0075$

$\pm 0.015$

The two longest periods may be caused by similar periodicities in the fluctuations of the shape of the earth's orbit (Mitchell, 1972). Attempts to correlate climate variation with other natural causes, such as sunspot cycles and related variations in the solar constant (Schneider and Mass, 1975) seem less well founded.

We are presently in a very warm period, about 10,000 years since the end of the last glacial. In the last 100 years the global mean temperature 


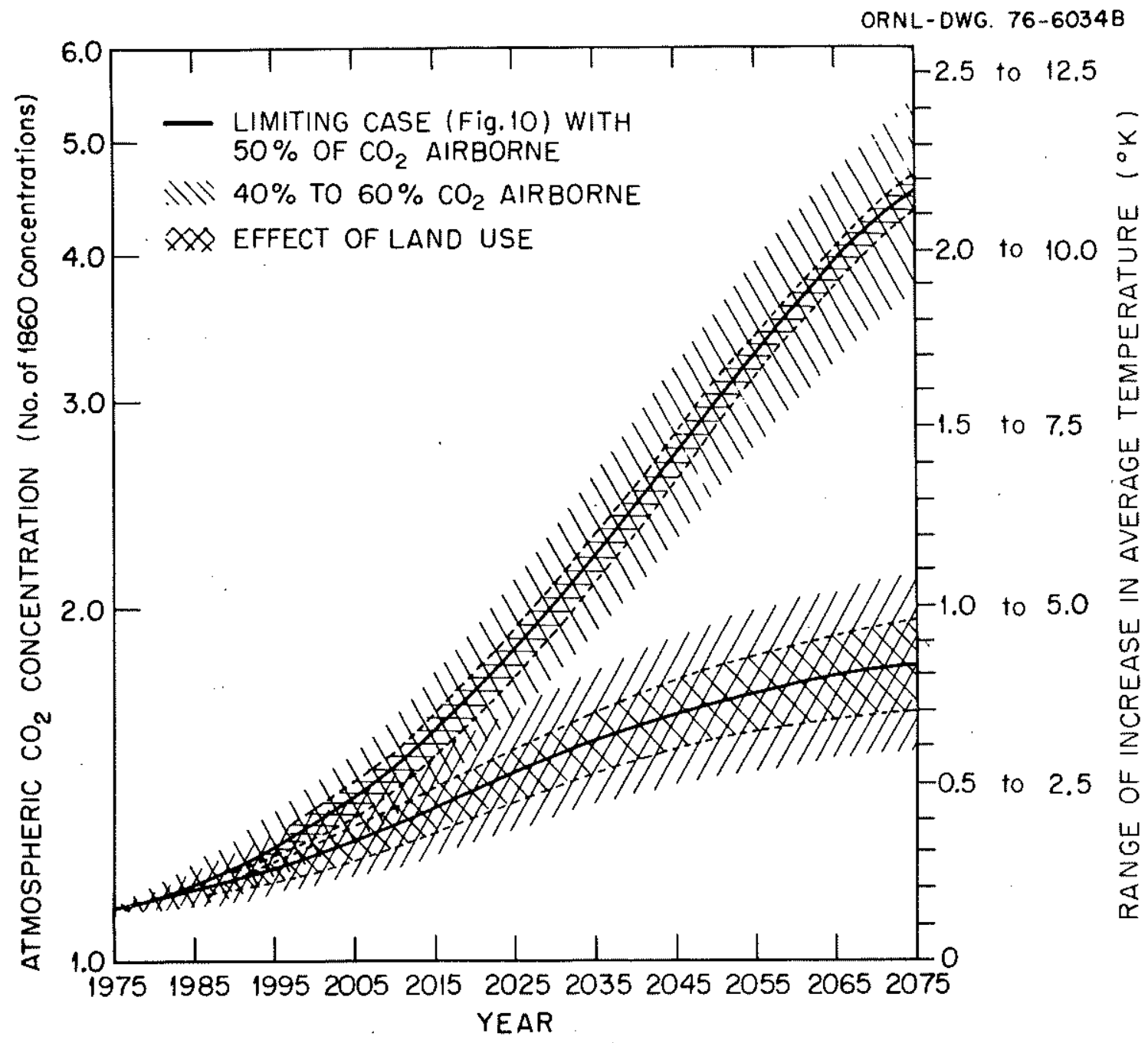

Fig. 12. Projected atmospheric $\mathrm{CO}_{2}$ concentrations and possible changes in the average surface temperature. 
rose about $0.6^{\circ} \mathrm{K}$ to 1940 and fell about $0.3^{\circ} \mathrm{K}$ in the following three decades (Mitche11; 1961, 1972). The important point to note is that the previous history of climate change suggests that natural fluctuations which occur rapidly enough (i.e., over a few generations) to produce easily recognized impacts on the affairs of man are likely to be of small amplitude. Over the next 100 years, for example, the mean global temperature may be expected to change no more than $0.5^{\circ}$ to $1.0^{\circ} \mathrm{K}$ from natural causes. Broecker's (1975) analysis suggests that after 1980 there will be an onset of natural warming (if warming does not occur sooner because of increased atmospheric $\mathrm{CO}_{2}$ ).

The major way in which the activities of man can be effective in changing climate is through the alteration of the thermal radiative balance of the earth. Introduction of particulates and aerosols into the atmosphere can result in either a warming or a cooling of the earth (Charlson and Pilat, 1969). Most atmospheric particles scatter solar radiation predominantly in the forward direction with a small fraction ( $10 \%$ ) in backward directions. The backscatter tends to increase the albedo of the atmospheric layer, but any change in the albedo of the earth-atmosphere system depends also on the albedo of the underlying surface (Mitchell, 1971). For each value of surface albedo, there is a critical ratio of absorbtion to backscatter of the aerosol which balances the heating and cooling effects. The particles which are produced by combustion of fossil fuels are relatively larger, usually remain at lower altitudes in the atmosphere, and stay airborne a relatively short time, thus having a limited and localized effect. From this consideration, it seems likely that the effect on climate of atmospheric particles from energy activities will be much smaller than the effects produced by $\mathrm{CO}_{2}$.

Modification of large surface areas changes the albedo from that of a natural state and will change the radiative balance. The introduction of certain absorbing gases into the atmosphere (e.g., water vapor and carbon dioxide) has a warming effect because they absorb infrared radiation from the earth's surface and from the clouds. These and other activities of man have their effects, taking place simultaneously, thereby making the physical evaluation of any one of them extremely difficult.

In most cases the impact to be expected from a particular stimulus 
has been deduced by resorting to models. Models for interpreting climatic change have been constructed for many factors, usually varying one at a time. To study the sensitivity of climate to $\mathrm{CO}_{2}$, simple one-dimensional radiation balance models of the atmosphere were developed initially. More recently, models of atmospheric circulation akin to those used in numerical weather prediction have been incorporated into so-called general circulation climate models. Such models indicate an increase in temperature with increased $\mathrm{CO}_{2}$, and suggest that the temperature response is approximately logarithmic, $i . e .$, each doubling in the concentration of $\mathrm{CO}_{2}$ produces about the same increase in the average temperature of the troposphere $(\Delta \mathrm{T})$. The more sophisticated models predict, moreover, that the temperature change is much greater at high latitudes. The amount of the average increase in temperature per doubling of $\mathrm{CO}_{2}$ given by the various models (Schneider, 1975) is in the range 0.7 to $9.6^{\circ} \mathrm{C}$. Schneider critically reviewed these models and concluded that "a state-of-the-art, order-ofmagnitude estimate" is in the range 1.5 to $3^{\circ} \mathrm{K}$. He notes, however, that this estimate could prove to be high or low by several fold as a result of "climate feedback mechanisms not properly accounted for in the state-ofthe-art models."

Some mechanisms not adequately accounted for in present models include:

(1) Decrease in average snow and ice coverage. This is a positive (amplifying) feedback mechanism, since the resulting decrease in reflected radiation (decrease in albedo) will produce further warming.

(2) Cloud Cover. The average percent of cloud cover and the average temperature of the cloud tops have an important effect on the heat balance calculations. Since a change of a few percent in the cloud cover could be as important as the primary effect of $\mathrm{CO}_{2}$ (Ramanathan, private communication), this is thought to be the most important feedback mechanism not now considered.

(3) Ocean Coupling. The most sophisticated calculations so far treat the oceans only as a source of water vapor. Exchange of heat and $\mathrm{CO}_{2}$ has not yet been included. Changes in ocean circulation and diffusive mixing cannot be predicted without a better model of ocean circulation. Since the latitudinal temperature gradient drives this circulation, the rate may decrease if high latitudes are warmed. 
(4) Biota Response. As noted earlier, the increased level of $\mathrm{CO}_{2}$ in the atmosphere may produce an increase in the net rate of photosynthesis tending to increase the biomass, perhaps partially a consequence of the warming of temperate climates and increased rainfall. This could be a negative feedback (damping) effect through the uptake and storage of $\mathrm{CO}_{2}$. However, present trends in land use (forest clearing) seem to be counteracting this opportunity for net increase in organic matter storage and climate moderation (SCEP, 1970; Attiwill, 1971; Woodwe11 and Pecan, 1973).

In addition to their differing magnitudes, these feedbacks have widely differing response times, from perhaps a few months for significant changes in average cloud cover to perhaps hundreds of years for significant changes in the extent of the polar ice caps. Since the sum of these feedback effects as a function of time is presently unknown, we will allow for their contribution to the relatively rapid climatic response by increasing Schneider's estimate of the range of the average $\Delta \mathrm{T}\left(1.5^{\circ}\right.$ to $\left.3^{\circ} \mathrm{K}\right)$ to $1^{\circ}$ to $5^{\circ} \mathrm{K}$ per doubling of the $\mathrm{CO}_{2}$ content of the atmosphere. This range of uncertainty in $\Delta \mathrm{T}$ is combined with the uncertainties associated with the growth in atmospheric $\mathrm{CO}_{2}$ to produce the range of projections in Figures 12 and 13 of the increase in the average surface temperature of the troposphere over the next 100 years.

The difference in the average surface temperature between a glacial and an interglacial period is about $5^{\circ} \mathrm{C}$. Thus, temperature changes near the upper limits of the projection in Figure 13 could be catastrophic. Except in the most optimistic case, it appears that increases in global average temperatures from anthropogenic factors will become larger than the natural variations in the fairly near future.

The small climatic changes which may occur between now and the year 2000 are apt to be great1y increased in the first several decades of the next century if fossil fuel consumption continues to accelerate beyond 2000. Barring extraordinary social-political steps toward energy conservation, not much can be done to stem consumption of fossil fuels over the next 25-30 years because only nuclear burners are a viable alternative during this period. (Hydrologic resources are an option in developing countries but only a very limited option in developed countries where they 


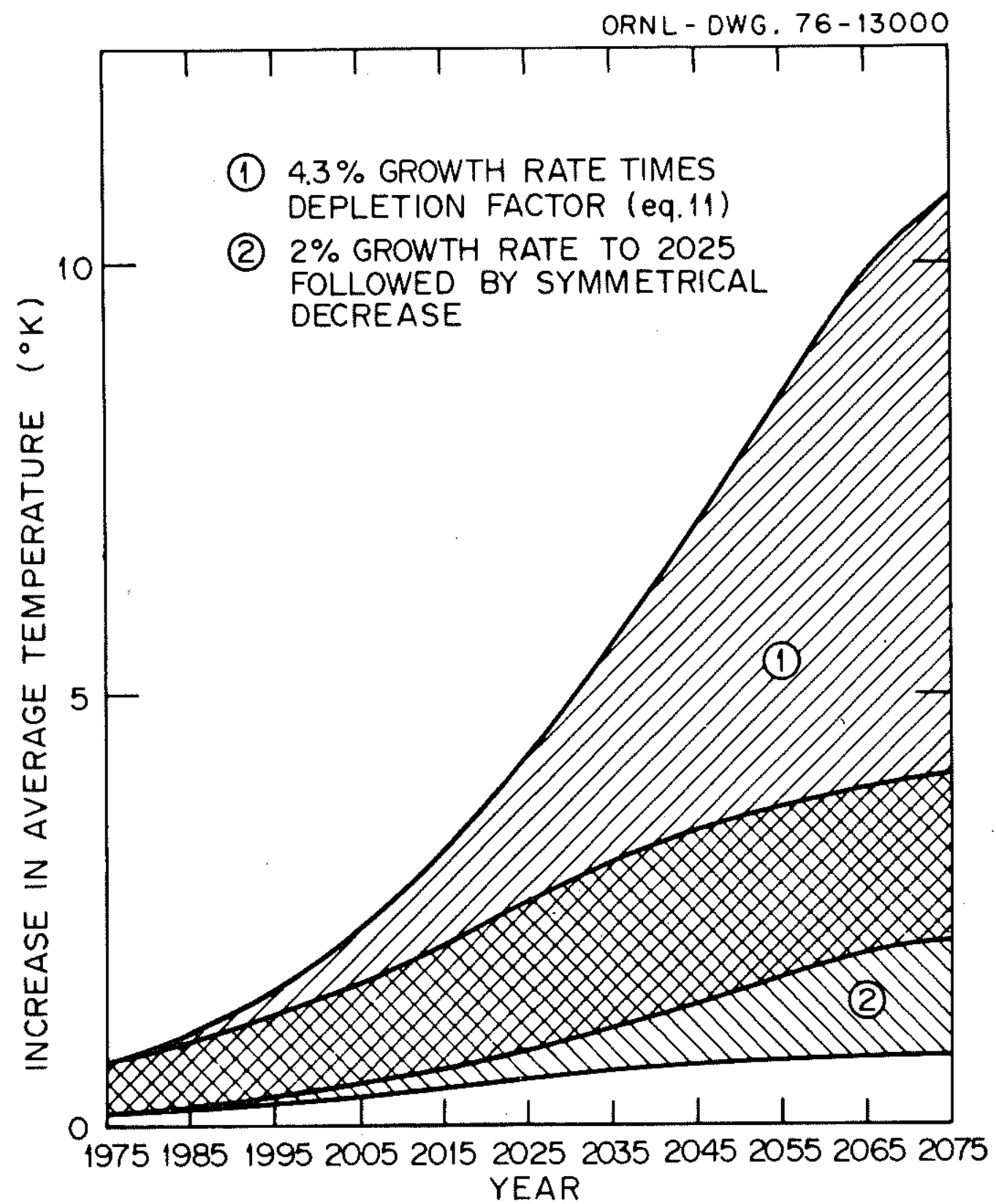

Fig. 13. Projected range of increase in average surface temperature for the limiting cases of fossil fuel use. $\Delta \mathrm{T}=1$ to $5^{\circ} \mathrm{K}$ per doubling of $\mathrm{CO}_{2}$ concentration. 
are already nearing full exploitation.) Hopefully, one or more of the unlimited "renewable" energy resources (fission breeder, fusion, or solar in -its many forms) can be fully developed and rapidly deployed early in the next century.

Concluding this section, the most important point to be made is that the effects of $\mathrm{CO}_{2}$ from fossil fuels, as presently projected (Figs. 12 and 13), range from possibly acceptable to catastrophic depending on the fossil energy scenario adopted and on the value chosen for $\Delta T$. Although the present state of knowledge does not warrant emergency countermeasures, greatly increased efforts must be made to foresee more clearly the consequences of the fossil fuel flux.

\subsection{Impacts of Climate Change}

While an increase in atmospheric $\mathrm{CO}_{2}$ should produce a general warming of world climate, the resulting impact on man and his environment obviously depends upon the nature and magnitude of regional climate changes and upon the rate at which they occur. Since at present these changes are even less predictable than the average $\Delta \mathrm{T}$, the possible impacts cannot be assessed in a usefully quantitative way, nor can any list of impacts be drawn up that would include a11, or perhaps even most, of the important effects.

We list here some effects of climate change that seem plausible enough, but these will suggest many other possible ones, some of which may prove quite harmful and some beneficial. In spite of the great uncertainties, the consequences of even small changes in regional climates are so important that our best efforts must be made to anticipate them.

\subsubsection{General Ecological Considerations}

An ecological assessment of the impacts of a general warming suggests that:

(1) Since the biological adaptations to a given region tend to be optimized by natural processes, relatively sudden changes in conditions will reduce fitness and/or productivity for many of the native species.

(2) Gross primary productivity (GPP) may increase, but respiration rates 
$\left(R_{g}\right)$ commonly do so more abruptly. Through artificial or natural selection, most crops and natural resource species grow best in zones where net primary production (NPP $=G P P-R_{g}$ ) is already high. Hence, warming is more likely than not to increase $\mathrm{R}_{\mathrm{g}}$ more than GPP and thereby decrease net photosynthetic production until better adapted genetic types take over.

(3) Microbial and insect pests from adjacent regions or endemic pests previously held in check may be favored, some producing severe effects on crops or native species.

(4) Plants can respond to warmer, drying conditions by water conserving mechanisms such as the closure of leaf pores (stomata) in the heat of the day, or the loss of leaves during periods of drought (Gates and Schmer1, 1975), but at the price of lowered productivity.

(5) Since the average rate of evaporation will tend to increase, the moisture requirements of the biota of each region will increase. Hence, the benefit of an increase in average precipitation will be reduced and the adverse effects of any decrease in precipitation will be enhanced.

(6) Increased impacts from extremes could follow the worldwide warming, especially in those areas where storm tracks shifted in directions to favor more dry, continental air masses. For example, strong winds without rain and adequate plant cover could bring "dust-bow1" storms to the Great Plains, more strongly and persistently than in the $1930^{\prime} \mathrm{s}$.

The combination of these effects could produce decreased biological and especially economic production in many large regions of all climatic zones but the wettest - despite longer growing seasons.

A full analysis of the ecological impacts of a given climate change in a given region requires detailed ecosystem models, including the sort described by Gates and Schmerl (1975), Botkin et al., (1973) and Shugart and West (1976). Such could be combined with biogeographic data banks to explore the extent and significance of climate shifts and biological interactions in a complex community. 


\subsubsection{Effects on Agriculture}

Year-to-year fluctuations in local weather are a fact of life in agriculture, but longer term fluctuations have produced considerable economic dislocation and human suffering in developed countries, and massive starvation in less developed regions. These larger, evidently natural fluctuations are likely to produce ever more serious effects as the growing world population presses agriculture to its limits of productivity. Clearly, then, still larger unfavorable changes in some regional climates are likely to produce dire consequences indeed, and the more so if they appear suddenly and are not anticipated.

Tropical agriculture may suffer the smallest specific effects, but even those may produce strongly adverse consequences in the aggregate among the large number of people that depend on it for subsistence. Moving poleward, it seems likely that increased warming will be accompanied by more dessication in many regions. This could produce crop shifts large enough to upset the established economic systems of states and nations, as well as patterns of world commerce. For example, wheat cropping, if diminished on the Great Plains, might displace maize in part of the Central Lowlands corn belt. More fertilizer and investment would be necessary for corn growth displaced increasingly to various forest soils. Long-season crops might extend northward onto the Boreal Zone (Fig. 5), but only with substantial cost of ameliorating poor soils (leached podsols) on recently glaciated terrain.

Rangelands and semiarid resources are marginal in hot and/or dry years in much of the western North America. Livestock must of ten be moved between woodlands, desert scrub, grasslands and feedlots, at appropriate seasons, or be sold at a loss when forage and/or water fail. If the projected climatic changes result in greater extremes, grazing, farming and direct human use of western lands could become even more difficult and risky.

\subsubsection{Shoreline Changes and Hydrologic Effects}

Perhaps the most often cited effect of a general warming is melting of the polar ice caps and the resulting rise in sea level. A complete melting would raise the water level over $50 \mathrm{~m}$, and just a partial melting would have 
profound effects on the shorelines of the world. However, the melting process may be quite complex and is not yet understood well enough to predict the rate at which this would occur. Warmer air alone could not produce a very rapid melting (Marland, private comrunication), but the surging of ice from continental shelves into the sea may be triggered under certain circumstances. Hughes (cited by Gribbin, 1976) suggests that surges from natural causes could produce a $5 \mathrm{~m}$ rise in sea level in the next 300 years.

Whereas increase in sea level is often cited as a long-term effect, the lowering water levels of inland lakes associated with possible drier climatic patterns may occur within a few years. For example, if lowering of the Great Lakes occurred, it would aggravate navigation and sewage disposal problems experienced during the last natural low fluctuation of Lakes Michigan-Huron (in 1964). Economic analysis would surely show many hundreds of millions of dollars at stake, considering (1) the replacement of facilities, (2) existing legal compacts that may have to be overridden, and (3) the time element in completing the necessary adjustments.

It is likely that climate shifts would cause changes in the water balance of whole states and regions, producing unreliable water supplies both on the surface and underground, and requiring large expenditures for remedial measures that would become necessary.

\subsubsection{0ther Impacts}

It is easy to deduce other effects of widely varying impact, both positive and negative -- but mostly negative. Many are sociological and political in character, and therefore extremely difficult or impossible to assess adequately. They involve equity and the ability to influence decisions by different groups who may view costs and benefits quite differently from one another. Because costs and benefits of climatic change will fall very unevenly on different regions, groups perceiving themselves unthreatened or even as beneficiaries of the change will question the validity or cost of steps that might be recognized elsewhere as desirable for correcting the situation. Groups in agricultural or urban regions quickly perceiving their own losses, and fearing more drastic changes yet to come, could look for scapegoats long before the several links from energy to atmospheric $\mathrm{CO}_{2}$ to climate to ecological and social 
impact can be regarded as settled from a scientific standpoint.

Another important impact that is very difficult to foresee is that on the productivity of the oceans. If the general upwelling of deep water (Section 2.3.3) were to diminish, then marine primary production, secondary production through animal food chains, and hence fishery success would diminish dramatically in the affected regions. Other aquatic food chains would be especially sensitive to changes in nursery grounds or other conditions along the immediate shore of oceans, lakes and major rivers.

Direct and subtle climatic effects on human health will be added to any consequence from irregular food supplies. Where winters become milder (especially above $60^{\circ}$ latitude) adverse effects of exposures to prolonged or extreme cold will be reduced. However, longer or more acute summer heat waves will increase discomfort and malaise for large populations in the temperate zone. Physiological stress will enhance risks of heat exhaustion, heat stroke, heart stress and debilitation, especially for individuals with chronic illness (Drs. T. A. Lincoln and A. S. Garrett, Jr., personal communication).

Separately, and especially taken together, with reasonable chance that many of these impacts will affect billions of people in a significant degree, a.lmost any summation of the possible social cost from excess $\mathrm{CO}_{2}$ becomes far too great to languish in the realm of academic debate. The possibility that (other) billions may find some benefits in the total change in no way dismisses the imperative to explore both costs and benefits, and the many kinds of data and inference which could improve their estimation and balancing.

Finally, there is also the really serious ethical question of the commitments which we and our children may be making for scores of generations to follow; the immediate commitment to the rapid consumption of the accessible reserves of f fossil carbon and the commitment to future changes in the world environment which seem impossible to reverse for many centuries to come. 


\section{ON-GOING RESEARCH AND FUNDING}

Judging from the rate of publications on the subject of the carbon dioxide question, interest in this matter is obviously widespread. Among the contributors are geologists, meteorologists, climatologists, physicists, chemists, oceanographers, biologists, and ecologists. The number of groups funded at a significant level to carry on work in this area seems to be quite limited, however, and in view of the possible importance of this problem, the total funding seems quite modest.

The summary of such U.S. Government supported work in Table 2 is based mainly on ERDA (1975) and the McCormack Committee Report (Caton et a1., 1976). In Table 3 are listed various individuals who have made notable contributions to the recent literature. (In most cases the source and current levels of funding are not known but the amounts are ' thought to be quite modest.) The broad categories in Table 2 (climate, oceans, carbon cycle, monitoring, climate impact) indicate what we consider to be the directly relevant work now going on.

It is not surprising that the National Oceanic and Atmospheric Administration (NOAA) has been committed to research in these areas. Moreover, much of the $\mathrm{CO}_{2}$ related effort has been associated with NOAA programs other than those listed in Table 2. The weather satellite program, research relating to ocean circulation, the climatological research of the Environmental Data Services, the atmospheric modeling of the Geophysical Fluid Dynamics Laboratory, and the geophysical monitoring of the Environmental Research Laboratories are examples of NOAA efforts which are conducted within established government organizational units as a part of the prescribed NOAA mission.

Additional work on terrestrial sources and sinks for $\mathrm{CO}_{2}$ is being carried out under programs primarily identified with ecosystem analysis. National Science Foundation's Analysis of Ecosystems Program, and related parts of ERDA's Environmental Program in the Division of Biomedical and Environmental Research have provided the historic leadership in the United States. In addition, the U.S. Department of Agriculture has supported a variety of practical studies on particular categories of forest and crop production, but other government agencies have had to provide the broader funding of biogeochemistry, and much of the significant plant physiology. 
Table 2. UiS. Government-Supported Programs, * Fj.scal Years 1975 or 1:.

\begin{tabular}{|c|c|c|c|c|}
\hline Institution & $\begin{array}{c}\text { Principal } \\
\text { Investigator }(s) \\
\end{array}$ & Funder & $\begin{array}{l}\text { Leve1 } \\
\underline{\underline{S} / \mathrm{yr}}\end{array}$ & Description \\
\hline \multicolumn{5}{|l|}{ Climate } \\
\hline $\begin{array}{l}\text { Geophysical Fluid Dynamics } \\
\text { Laboratory (GFDL), NOAA, } \\
\text { Princeton, NJ }\end{array}$ & $\begin{array}{l}\text { S. Manabe } \\
\text { J. Smagorinsky }\end{array}$ & $\begin{array}{l}\text { Internal } \\
\text { (NOAA) }\end{array}$ & & Climate modeling \\
\hline $\begin{array}{l}\text { National Center for Atmos- } \\
\text { pheric Research (NCAR), } \\
\text { Boulder, co }\end{array}$ & $\begin{array}{l}\text { S. Schneider } \\
\text { W. W. Kellogg } \\
\text { W. M. Washington }\end{array}$ & $\begin{array}{l}\text { NSF } \\
\text { NSF } \\
\text { NSF }\end{array}$ & 500 & $\begin{array}{l}\text { Climate modeling, } \\
\text { global radiation balance }\end{array}$ \\
\hline $\begin{array}{l}\text { Colorado State University } \\
\text { Fort Collins, Co }\end{array}$ & T. Vonderhaar & NASA & & Global radiation \\
\hline $\begin{array}{l}\text { Langely Research Center } \\
\text { Hampton, VA. }\end{array}$ & $\begin{array}{l}\text { V. Ramanathan } \\
\text { (now NCAR) }\end{array}$ & NASA & & Climate modeling \\
\hline $\begin{array}{l}\text { RAND Corporation } \\
\text { Santa Monica, CA }\end{array}$ & W. L. Gates & \multicolumn{2}{|l|}{ DOD (ARPA) } & Climate modeling \\
\hline $\begin{array}{l}\text { Goddard Institute of Space } \\
\text { Science, New York, NY }\end{array}$ & $\begin{array}{l}\text { W. Quirk } \\
\text { R. Jastrow } \\
\text { P. Stone (joint }\end{array}$ & \multicolumn{2}{|l|}{ NASA } & C1imate modeling \\
\hline $\begin{array}{l}\text { MIT, Dept. of Meteorology, } \\
\text { Cambridge, MA }\end{array}$ & $\begin{array}{l}\text { R. E. Newe1l } \\
\text { J. Charney }\end{array}$ & $\begin{array}{l}\text { NSF } \\
\text { ERDA/BER }\end{array}$ & $\begin{array}{l}100 \\
100\end{array}$ & Climate modeling \\
\hline $\begin{array}{l}\text { University of Arizona } \\
\text { Tucson, AZ }\end{array}$ & W. D. Sellers & NSF & 31 & Climate modeling \\
\hline $\begin{array}{l}\text { University of Wisconsin } \\
\text { Madison, WI. }\end{array}$ & $\begin{array}{l}\text { R. A. Bryson } \\
\text { J. E. Kutzbach }\end{array}$ & NSF & 100 & Climate modeling \\
\hline \multicolumn{5}{|l|}{ Oceans } \\
\hline $\begin{array}{l}\text { University of California } \\
\text { at San Diego, Scripps } \\
\text { Institute of Oceanography } \\
\text { La Jolla, CA }\end{array}$ & $\begin{array}{l}\text { H. Craig } \\
\text { J. Lupton } \\
\text { G. Namias } \\
\text { Kenyon, et a1. }\end{array}$ & $\begin{array}{l}\text { NSF } \\
\text { NSF } \\
\text { NSF }\end{array}$ & $\begin{array}{l}150 \\
277 \\
120\end{array}$ & $\begin{array}{l}\text { Ocean circulation, } \\
\text { atmosphere, geochemlstry, } \\
\text { ocean-atm. coupling, } \\
\text { ocean clrculation }\end{array}$ \\
\hline $\begin{array}{l}\text { Oregon State University } \\
\text { Corvallis, OR }\end{array}$ & $\begin{array}{l}\text { J. S. Allen } \\
\text { W. Quinn }\end{array}$ & NSF & $\begin{array}{l}90 \\
46\end{array}$ & $\begin{array}{l}\text { Ocean circulation, } \\
\text { ocean-atm. coupling }\end{array}$ \\
\hline $\begin{array}{l}\text { Lamont-Doherty Geologica1 } \\
\text { Observatory, PaIllsades, NY }\end{array}$ & W. Broecker & $\begin{array}{l}\text { NSF } \\
\text { ONR } \\
\text { ERDA/BER }\end{array}$ & $\begin{array}{r}142 \\
40\end{array}$ & $\begin{array}{l}\text { Ocean circulation, } \\
\text { chemistry fluxes }\end{array}$ \\
\hline $\begin{array}{l}\text { Geophysical Fluid Dynamics } \\
\text { Laboratory (GFDL), NOAA, } \\
\text { Princeton, NJ. }\end{array}$ & K. Bryan & NOAA & & Ocean circulation \\
\hline $\begin{array}{l}\text { UCLA, Dept. of Meteorology, } \\
\text { Los Angeles, CA }\end{array}$ & $\begin{array}{l}\text { Y. Mintz, et al. } \\
\text { K. Takano }\end{array}$ & $\begin{array}{l}\text { NSF } \\
\text { NASA }\end{array}$ & 225 & $\begin{array}{l}\text { Ocean modeling } \\
\text { atmosphere }\end{array}$ \\
\hline $\begin{array}{l}\text { National Marine Fisherles } \\
\text { Service, NOAA, Monterey, CA }\end{array}$ & $\begin{array}{l}\text { J. B. Johnson } \\
\text { D. R. McClaln }\end{array}$ & $\begin{array}{l}\text { Internal } \\
\text { (NOAA) }\end{array}$ & & $\begin{array}{l}\text { Large scale } \\
\text { afr-sea Interactions }\end{array}$ \\
\hline $\begin{array}{l}\text { Nationa1 Marine Fisheries } \\
\text { Service, Seattle, WA }\end{array}$ & $\begin{array}{l}\text { T. Joyner } \\
\text { V. W. Conrad }\end{array}$ & $\begin{array}{l}\text { Internal } \\
\text { (NOAA) }\end{array}$ & & $\begin{array}{l}\text { Future fishery } \\
\text { resources }\end{array}$ \\
\hline
\end{tabular}


Table 2. U.S. Government-Supported Programs (Cont1nued)

\begin{tabular}{|c|c|c|c|c|}
\hline Institution & $\begin{array}{c}\text { Principa1 } \\
\text { Investigator(s) } \\
\end{array}$ & Funder & $\begin{array}{l}\text { Leve1 } \\
\underline{\mathrm{S}} / \mathrm{yx} \\
\end{array}$ & Description \\
\hline $\begin{array}{l}\text { Dept. of Oceanography, } \\
\text { University of Washington } \\
\text { Seattle, WA }\end{array}$ & $\begin{array}{l}\text { R. Dugdale } \\
\text { J. C. Kelley, et } \\
\text { M. Stevenson, et } \\
\text { D. Halpern, et al. }\end{array}$ & $\begin{array}{l}\text { NSF } \\
\text { a1. NSF } \\
\text { a1. ONR } \\
\text {. }\end{array}$ & 1100 & $\begin{array}{l}\text { Coastal upwelling } \\
\text { ecosystem analysis }\end{array}$ \\
\hline $\begin{array}{l}\text { Woods Hole Oceanographic } \\
\text { Institute, Woods Hole, MA }\end{array}$ & $\begin{array}{l}\text { W. Metcalf } \\
\text { F. Schroeder }\end{array}$ & NSF & 49 & Ocean thermal data \\
\hline $\begin{array}{l}\text { Yale University } \\
\text { New Haven, CN }\end{array}$ & Berner & NSF & 36 & $\mathrm{CaCO}_{3}$ reaction kinetics \\
\hline $\begin{array}{l}\text { Florida State UnIversity } \\
\text { Tallahassee, FA }\end{array}$ & Morse & NSF & 33 & $\mathrm{CaCO}_{3}$ reaction kinetics \\
\hline Carbon Cycle & & & & \\
\hline $\begin{array}{l}\text { Untversity of California } \\
\text { at San Diego, Scrlpps } \\
\text { Institute of Oceanography } \\
\text { La Jolla, CA }\end{array}$ & H. Suess & NSF & 145 & $\begin{array}{l}{ }^{14} \mathrm{C} \text { as a tracer in the } \\
\text { carbon cycle }\end{array}$ \\
\hline $\begin{array}{l}\text { Argonne National Laboratory } \\
\text { Lemonte, IL }\end{array}$ & J. Gray & ERDA/BER & 42 & ${ }^{14} \mathrm{C}$ in stratosphere \\
\hline $\begin{array}{l}\text { Texas A \& M University } \\
\text { College Station, TX }\end{array}$ & W. M. Sackett & NSF & 44.3 & $\begin{array}{l}\text { Marine geochemistry } \\
\text { of }{ }^{13} \mathrm{C} \text { and }{ }^{14} \mathrm{C}\end{array}$ \\
\hline $\begin{array}{l}\text { University of Washington } \\
\text { Seattle, WA }\end{array}$ & M. Stulver & NSF & 30 & $\begin{array}{l}{ }^{14} \mathrm{C} \text { cycling and } \\
\text { chronology }\end{array}$ \\
\hline $\begin{array}{l}\text { University of Arizona } \\
\text { Tucson, AZ }\end{array}$ & P. E. Damon & NSE & 71 & $\begin{array}{l}{ }^{14} \mathrm{C} \text { cycling and } \\
\text { chronology }\end{array}$ \\
\hline $\begin{array}{l}\text { Institute for Space Studies } \\
\text { Goddard Space Flight Center } \\
\text { NASA, NY }\end{array}$ & M. I. Hoffert & NASA & & $\begin{array}{l}\text { Model including } \\
\text { latitude variations }\end{array}$ \\
\hline \multicolumn{5}{|l|}{ Monitoring } \\
\hline $\begin{array}{l}\text { Environmental Research } \\
\text { Laboratory, NOAA, } \\
\text { Boulder, CO }\end{array}$ & $\begin{array}{l}\text { K. Hansen } \\
\text { J. Miller } \\
\text { J. Watkins }\end{array}$ & $\begin{array}{l}\text { Internal } \\
\text { (NOAA) }\end{array}$ & $1700(?)$ & $\begin{array}{l}\text { Accumulation of long- } \\
\text { term atmospheric data; } \\
\text { levels of } 0^{3}, 0^{2} \text {, } \\
\text { aerosols, etc; data } \\
\text { analysis and compllation }\end{array}$ \\
\hline $\begin{array}{l}\text { University of Calffornia } \\
\text { at San Diego, Scripps } \\
\text { Institute of Oceanography } \\
\text { La Jolla, CA }\end{array}$ & C. D. Keeling & NSF & 143 & $\begin{array}{l}\text { Measurement, analysis } \\
\text { of data on } \mathrm{CO}_{2} \text { content } \\
\text { of atmosphere, } \\
\text { model testing }\end{array}$ \\
\hline $\begin{array}{l}\text { Untversity of Wisconsin } \\
\text { Madison, WI }\end{array}$ & $\begin{array}{l}\text { V. Suomi } \\
\text { Sikdar }\end{array}$ & NSF & 101 & $\begin{array}{l}\text { Global monitoring } \\
\text { (for GARP) }\end{array}$ \\
\hline $\begin{array}{l}\text { Cornel1 University } \\
\text { Ithaca, NY }\end{array}$ & R. M. Roth & $\begin{array}{l}\text { NASA } \\
\text { USDA }\end{array}$ & & $\begin{array}{l}\text { Satellite measure of } \\
\text { season shifts }\end{array}$ \\
\hline
\end{tabular}


Table 2. U.S. Government-Supported Programs (Continued)

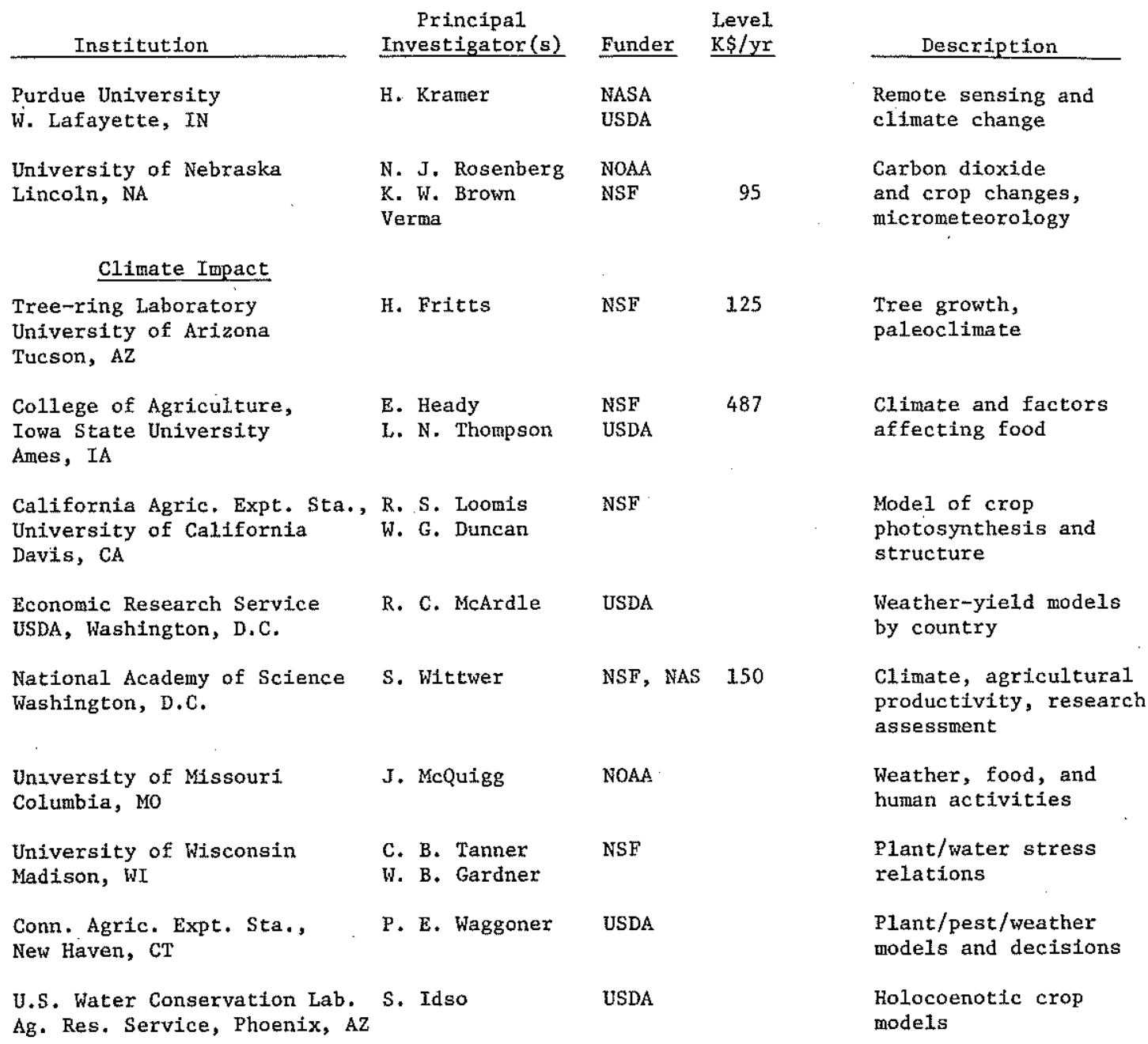

* Source: ERDA (1975), Caton et al., (1976), and private communication. 
Table 3. Other Contributors

\section{Investigator}

N. I. Bazilevich

W. Bischof

S. F. Biske

V. S. Volka

o. Björkman

H. Mooney

B. Bolin

R. A. Bryson

M. I. Budyko

J. S. Bunt

R. W. Burling

K. W. Butzer

W. Dansgaard

E. S. Deevey, Jr.

C. T. deWIt

\section{Institution}

Dokuchaev Soil Institute Moscow, USSR

Institute of Meteorology University of Stockholm, Sweden

Geology Institute Academgorodoka, Novosibirsk USSR

Biological Sciences Stanford University Palo Alto, CA

Department of Meteorology University of Stockholm, and International Meteorological Institute of Stockholm, Sweden

Institute for Environmental Studies, University of Wisconsin, Madison, WI

Geophysical Observatory, Leningrad, USSR

Australian Institute of Marine Science

Townsville, Queensland, Australia

Institute of Oceanography University of British Columbia V6T 1W5, Canada

Geography, University of Chicago Chicago, IL

Geophysical Isotope Lab. University of CoDenhagen, Denmark

Florida State Museum

University of Florida

Gainesville, FA

Institute of Biological Sclences University of Wageningen, Netherlands

\section{Interest}

World carbon cycle

$\mathrm{CO}_{2}$ concentration in atmosphere

Post glacial climate change and pollen

Adaptations of physiology and ecology to environment

climate, carbon cycle

Climate

Radiation and climate

Marine productivity

$\mathrm{CO}_{2}$ circulation in oceans

Environmental archeology

Radiocarbon dating and history

Palynology, biogeochemistry

Physiological models of crops and environment 
Table 3. Other Contributors (Continued)

Investigator

C. Emiliani

E. Eriksson

N. Ersus

K. Becker

K. Faegri

R. W. Fairbridge

A. W. Strahler

A. W. Falrhall

H. F1öhn

R. M. Garre1s

J. R. Garrett

C. Hall

G. Likens

W. F. Harris

H. D. Holland

T. Hughes

v. Kovda

\section{Institution}

Marine and Atmospheric Sci. University of Miami, FA

University of Uppsala, Sweden

Statistics, Economics and Social Pollcy, FAo, Rome, Italy

Botany, Bergen University, Bergen, Norway

Dept. of Geology Columbia University, New York, NY University of Washington Seattle, WA

Meteorological Institute Bonn University of West Germany

Department of Geology Northwestern Unfversity Evanston, IL

Commonwealth Scientific and Industrial Research Organization (CSIRO), Division of Atm. Physics. Aspendale, Victoria, Australia

Ecology and Systematics

Cornel1 University

Ithaca, NY

Environmental Sciences Division Oak Ridge National Laboratory Oak Ridge, TN

Department of Geology Harvard University Cambridge, MA

University of Maine

Moscow State University MosCOW, USSR
Department of Chemistry
Interest

Oxygen Isotopes and ocean temperature history

Mathematics of carbon cycle

Populations, trade predictions and future food supplies

Palynology and biogeography

Sealevel changes and geomorphic change

$\mathrm{CO}_{2}$ ocean chemistry

Meteorology and climatology

Geochemistry

$\mathrm{CO}_{2}$ in the atmosphere

Aquatic productivity and exchange rates

Terrestrial productivity, radiocarbon assessment

Chemlcal oceanography, history of the oceans

Glacial melting

Distribution and modification of solls 
Table 3. Other Contributors (Continued)

Invest1gator

H. H. Lamb

H. E. Landsberg

E. Lemon

L. H. Allen

H. Lieth

W. F. Libby

R. Berger

L. Machta

G. I. Marchuk

D. H. Miller

J. M. Mitche11

R. Nydal

H. Oeschger, et al.

J. S. O1son

I. U. 01sson

G. I. Pearman California, Los Angeles, CA

Technological Institute Untversity, Sweden
Institution

School of Environmental Sci. University of East Anglia Norwich, United Kingdom

University of Maryland, College Park, MD

U.S. Department of Agriculture Ithaca, NY

Botany Department, University of North Carolina Chapel Hill, NC

Dept. of Chemistry, University of Radiocarbon

Air Research Laboratory, NOAA Silver Spring, MD

USSR Academy of Science Academgorodoka, Novosibirsk USSR

Department of Geological Sciences University of Wisconsin

Environmenta1 Data Service, NOAA, Silver Spring, MD

Physics Department

Trondheim, Norway

Physics Institute, University of Bern, Switzerland

Environmental Sciences Division Oak Ridge National Laboratory Oak Ridge, TN

Institute of Physics, Uppsala

CSIRO, DIviston of Acm. Physics Aspendale, Victoria, Australia
Interest

Climate change and impacts

Meteorology and climate

Photosynthesis balance, especially in crops

Mapping of global production estimates

$\mathrm{CO}_{2}$ in the atmosphere

Mathematics and physics of climate predictions, etc.

Climate

Climate change

Radiocarbon trends, especially atmospheric

Oceanographic models

Biosphere, carbon cycles and climatic risks

Radiocarbon dating

$\mathrm{CO}_{2}$ in the atmosphere 
Table 3. Other Contributors (Continued)

Investigator

T. Rafter

D. Reichle

H. Shugart

W. A. Reiners

G. A. Riley

P. J. Wangersky

R. Rotty

J. H. Ryther

V. Smil

D. Milton

J. D. H. Strickland

J. Terasmae

R. G. West

J. H. Whittaker

G. Woodwel1

D. Botkin

H. E. Wright

\section{Institution}

Institute of Nuclear Studies Lower Hutt, New Zealand

Environmental Sciences Division Oak Ridge National Laboratory Oak Ridge, TN

Biological Sciences

Dartmouth College

Hanover, NH

Institute of Oceanography

Dalhousie Unlversity

Halifax, Nova Scotia

Institute for Energy Analysis Oak Ridge Associated Universities Oak Ridge, TN

Woods Hole Oceanographic Inst. Woods Hole, MA

Geography, University of Manitoba Winnipeg, Manitoba

Institute of Marine Resources University of California, La Jo1la, CA

Botany, Brock University

St. Catherines, Ontario

Quaternary Research, Botany Cambridge Untversity, U.K.

Ecology and Systematics Cornell University

Ithaca, $\mathrm{NY}$

Marine Biological Laboratory Woods Hole, MA

Limology, Earth Sclence, University of Minnesota, Minneapolis, MN

\section{Interest}

Radiocarbon trends in air and organic matter (southern hemisphere)

Ecosystem analysis, resource competition

Decomposers and organic matter

Marine Productivity and rrganic matter

Atmospheric $\mathrm{CO}_{2}$, fossil fuel fluxes

Marine primary and secondary productivity

Alternative futures for $\mathrm{CO}_{2}$ and climate

Plankton and primary productivity

Glaclal-Interglaclal blogeography

Pleistocene history and blogeography

Terrestrial communities and productivity

Ecological contributions to the carbon cycle

Glacial-interglacial geomorphology and pollen 
The U.S. Department of Interior carries on important work, in the USGS, on a variety of studies relevant to future land use of ecosystems.

Several organizations have sponsored cooperative international efforts and long range planning activities related to the $\mathrm{CO}_{2}$ problem. Most important among these is the Global Atmospheric Research Program (GARP) of the World Meteorological Organization, International Council of Scientific Unions. Their recent publication "The Physical Basis of Climate and Climate Modeling", a report of the International Study Conference in Stockholm (GARP, 1975), is a noteworthy example of their efforts. The United States Committee for GARP recently published another notable report "Understanding Climate Change, A Program for Action" (NAS, 1975). The Federal Council for Science and Technology recently sponsored an Ad Hoc Panel on the Present Interglacial (ICAS, 1974) which surveyed the state of knowledge of what is known about predicting climatic change.

The Interior and State Departments, and committees involving other segments of the U.S. Government have been laying a groundwork for American participation in the Man and Biosphere (MAB) program. This program is coordinated by UNESCO, the FAO (Food and Agricultural Organization), and the UNEP (United Nations Environmental Program). In the nongovernmental sphere (as distinct from the intergovernmental) SCOPE (Scientific Committee on Problems of the Environment, of ICSU, the International Council of Scientific Unions) has been organizing a core program since 1973, as the Special Committee for the International Biological Program (SCIBP) approached its scheduled termination. A general theme of SCOPE on geochemical cycles, with a particular proposed but unfunded activity on the carbon cycle, provides one channel for encouraging the international activity which is badly needed in this area. 


\section{RECOMMENDATIONS AND CONCLUSIONS}

Revelle and Suess (1957) stated: "Human beings are now carrying out a large scale geophysical experiment of a kind that could not have happened in the past nor be repeated in the future. Within a few centuries we are returning to the atmosphere and oceans the concentrated organic carbon stored in the sedimentary rocks over hundreds of millions of years. This experiment, if adequately documented, may yield a far-reaching insight into the processes determining weather and climate." Thus well stated is the case for vigilant and diligent observation of the consequences of the anthropogenic flux of $\mathrm{CO}_{2}$ to the atmosphere. Left unstated, however, is perhaps the greater need to anticipate the consequences well enough to keep them within acceptable limits.

The problem must be treated in a holistic manner but has distinct parts:

(1) To understand the carbon cycle sufficiently to predict the future atmospheric concentration of carbon dioxide for various fuel scenarios.

(2) To predict the spatial and temporal pattern of global climate change resulting from a known (or assumed) change in the atmospheric $\mathrm{CO}_{2}$ concentration.

(3) To evaluate the impact that a given (or predicted) climate change will have on man, his ecological and social environments.

In the following sections we will consider each of these parts of the problem in more detail. Because the $\mathrm{CO}_{2}$ problem has resulted largely from the energy-producing activities of the developed countries, the responsibility for dealing with it rests largely with them. As the agency responsible for energy development in the U.S., ERDA will wish to participate fully in the variety of activities that, in all probability, will develop as part of a global effort to deal with the problem. On the one hand, if the $\mathrm{CO}_{2}$ problem turns out to be minor or insignificant, a large impediment to the accelerated and unlimited use of coal and oil shale will have been removed. If, on the other hand, continued increased addition of $\mathrm{CO}_{2}$ to the atmosphere is early shown to be a threat, early de-emphasis of coal use, accelerated implementation of nuclear (particularly breeder) energy, speeded development of fusion, solar and other renewable forms of energy, and at least increased interim energy conservation must all receive high priority. 
4.1 Understanding The Carbon Cycle

There are two major exchanges of atmospheric $\mathrm{CO}_{2}$ : the $\mathrm{CO}_{2}$ fluxes between the atmosphere and the oceans, and the $\mathrm{CO}_{2}$ fluxes between the atmosphere and the terrestrial biosphere. About both there is insufficient quantitative information or understanding to predict future concentrations of $\mathrm{CO}_{2}$ in the atmosphere.

The flux of $\mathrm{CO}_{2}$ from the oceans has not been measured directly. It has been deduced approximately from box models, which seem to give low values, and perhaps more reliably from models that include diffusive mixing through the thermocline (Oeschger et. al., 1975). This net flux, which may be quite large, must be better measured and better understood than at present. Circulation models being developed for the oceans may be one means of accomplishing this, and these may emerge naturally as a part of the modeling effort (Bolin, 1974).

But a greatly increased ocean monitoring effort is also called for, one that would provide information at a level of detail more comparable to that of the atmosphere. Techniques have been developed (Keeling, 1968) for ship-board measurement of the partial pressure of $\mathrm{CO}_{2}$ in surface water and of that in the supernatant atmosphere. While such measurements would not be sensitive enough to show the integrated flux of $\mathrm{CO}_{2}$, if made routinely by automated equipment on a fraction of the world's ships, they could lead to a greatly improved knowledge of the circulation of $\mathrm{CO}_{2}$.

The deep ocean circulation is difficult to study, and progress here will depend on the development of new techniques of measurement, as well as the vigorous application of existing ones. Broecker (private communications) suggests that the distribution of tritium from nuclear testing and its daughter ${ }^{3} \mathrm{He}$ is an ideal tracer for such studies, and that such measurements in key areas of the ocean, along with periodic surveys of major regions should be emphasized in a program to determine the fate of fossil fuel $\mathrm{CO}_{2}$. In all ocean monitoring activities, and especially in the study of deep circulation and $\mathrm{CaCO}_{3}$ reaction rates, the collection of data and the development of circulation models should be closely coupled.

Because of the wide variation of local $\mathrm{CO}_{2}$ fluxes, there can be little hope of deducing from direct measurement the net terrestrial flux to or from the atmosphere. This can no doubt be obtained more accurately from 
the monitoring of changes in the biomass, patterns of land use, burning, and in the use of biomass as fuel. The monitoring and modeling of terrestrial fluxes may require an effort at least as extensive as that for the oceans. Terrestrial monitoring, assessment and research are all important because land is the only region of the carbon cycle, aside from fossil fuel fluxes, over which man can hope to exercise any effective control. of greatest priority for ERDA should be the linkage between man's $\mathrm{CO}_{2}$ production and biospheric change. Specific topics of interest include:

(1) The release of $\mathrm{CO}_{2}$ by fires; (2) actual and potential use of biomass as fuel; (3) trends of forest clearing and reversion to woods or other vegetation; (4) residence times of live and dead organic components on land; (5) the ecological (field) response as well as physiology of enhanced $\mathrm{CO}_{2}$ intake. The monitoring involved in these activities will require ingenious use of satellite imagery in representative biome regions, calibrated by ground truth studies.

\subsection{Predicting Climate Change}

There is much in the area of climate change which is not understood in a quantitative sense. Only through the interaction of careful thought, analysis of valid observational data, and skillful use of computer modeling can one expect to quantitatively evaluate potential climate change.

The Global Atmospheric Research Program (GARP) offers much hope of mobilizing the scientific community to seek a better understanding of climate change. As in most international ventures, the early progress will likely be slow and heavily biased to planning. From ERDA's standpoint, participation and support of the GARP effort is essential, but probably not sufficient. ERDA must have better measures of the possible climatic effects than are now known, and this information must be available soon, if suitable planning for transition from one energy source to another is to be accomplished.

It has been the precise measurement of the concentration of $\mathrm{CO}_{2}$ in the atmosphere, conducted on a systematic basis only since 1958, that has most clearly recorded the course of the great. "Geophysical Experiment." The number of monitoring stations (present1y 4, operated by NOAA) should be increased in a cooperative international effort so that the seasonal 
changes can be monitored more systematically over the surface of the earth. It is important that all measurements employ a standardized method producing results free of systematic calibration errors.

Although an abundance of meteorological data is regularly collected and archived, it is representative of a relatively small portion of the earth's surface, mostly in the northern hemisphere. Large inaccessible areas of underdeveloped nations as well as vast regions of the ocean are not monitored on a regular basis. More extensive ground-based observational networks are needed to provide accurate, reliable world-wide data on temperature, humidity, precipitation, barometric pressure, winds, etc. Systematic analysis of these data would provide an integrated, nearly real-time "state of the world climate" that is much needed. GARP and the NOAAGeophysical Monitoring for Climatic Change programs are moving in this direction, but acceleration of the effort is necessary.

Continuous monitoring by satellites should be vigorously developed. Sea surface temperature, extent of ice cover, albedo, extent of cloud cover, and the solar constant, are now being measured. Measurements of cloud variables (e.g., cloud type, thickness, elevation, temperature at top) should be developed and included in this program.

Climate models have evolved since the 1950's from primitive onedimensional, radiation-balance models of the atmosphere to the present general circulation models that describe a three-dimensional atmosphere and, in a primitive way, its interaction with the snow and ice (cryosphere), oceans and land. Simultaneously under development are circulation models of the oceans (hydrosphere). Yet to be accomplished is a satisfactory coupling of models of these fluid reservoirs.

Such models consume great amounts of time on large computers, but advances in computer technology now in sight may permit reductions in running time of perhaps a factor of ten. Mitchel1 (private communication) predicts that in about a decade much more detailed global climate models will be developed that describe climate adequately on a fairly fine global grid, and it is his hope that insights thus gained will lead to simplified "smart" models that can make the needed predictions much more efficiently. Many other scientists working in this field feel that we are at least ten years away from accurate estimates of the climate change resulting from 
increased atmospheric $\mathrm{CO}_{2}$ - as well as the effects on climate of atmospheric dust and aerosols, and atmospheric thermal pollution. Some hold the view that substantial progress with, numerical models must await improved understanding of certain underlying physical phenomena. In particular, these include: (1) improved means of the direct solution of the equations governing fluid dynamics, and (2) better understanding and/or representation of cloud formation and interactions.

The need for climate prediction (to say nothing of its economic value) is so great and the difficulty of achieving it so formidable that we recommend as the first priority a much larger climate study effort be undertaken. It should be a broad program that includes all aspects of climatology. It should certainly include: (1) numerical modeling, (2) physical modeling, (3) basic studies of fluid dynamics, (4) studies of cloud formation and interactions, (5) systematic surface observations of climatic variables throughout the world, (6) atmospheric monitoring by satellites, and (7) statistical analysis of observational data. The staff for such a program should include in addition to meteorologists and climatologists representatives from the physical and engineering sciences. What seems most needed (Manabe, private communication) for more rapid progress in climate research are new ideas and insights that might replace the "brute force" methods of numerical computation with elegant simplifications ideas and insights that are most likely to come from the bringing together of workers with diverse backgrounds.

\subsection{Evaluating the Consequences of Climate Change}

When it becomes possible to foresee the changes in regional climate that will result from the increase in anthropogenic $\mathrm{CO}_{2}$, there remains the formidable task of anticipating the ecological, economic, social, and political impacts quickly enough and accurately enough to take the necessary remedial actions. Obviously the sooner climate change and the resulting impacts can be foreseen, the more likely it is that effective action can be taken. But these assessments are of a highly interdisciplinary nature and of a scope which is quite unprecedented; hence, success will probably require: (1) the development of more effective procedures of information handling and of modeling; (2) the development of methods for validation of 
the models and scenarios that will provide the necessary credibility; and (3) the establishment of improved organizational structures to insure adequate interdisciplinary communication and cooperation. In short, the immediate problem is to develop the means for credible assessment of the impacts of climate change. In the following paragraphs we make specific recommendations for the development and testing of these means.

While much of the diverse information needed already exists, additional new data and evaluations must be obtained for affected regions by climatologists, biologists, agronomists, other resource managers, geologists, geographers, economists and demographers. These data and judgments must be organized across disciplinary lines, and models developed that can take account of all the interacting effects of a balanced impact scenario.

Biophysical ecology and physiology provide valid principles for estimating how individual organisms and species can adjust their seasonal and life cycles to adapt to given climatic changes. For species populations, models can and should be modified to distinguish changes in crops and other plant and animal communities so that an appropriate weighted average can be made for regions and eventually larger areas of continents. Effects of burning, harvest and other human impacts must be introduced, so that feedbacks to the rest of the system can be followed. Regional shifts in life zones should be translated into rate of biological (especially agricultural) production. The full impact of regional changes in water balance should be included, along with shoreline studies where important, as in the Great Lakes region. The effects of various rates of glacial melting should be translated into estimates of the cost of land and property loss, especially for the Atlantic and Gulf coasts where substantial amounts of land and all its associated values are involved. Clearly several kinds of environmental research must be continued and increased in support of these models and climatic assessments.

Validation of the models must be carried out to the fullest extent possible at every stage. Beyond demonstrating that models are consistent with data upon which they are formulated and tuned, it is essential to find ways of testing their consistency with independent experience. Analysis of places and times with unusual deviation from "normal" (e.g., the dustbowl and the Irish potato famine) will suggest the kinds of perturbations which 
may be expected in decades ahead.

All of the foregoing efforts will require means for the many disciplines to work together, not merely to communicate their separate results. Ad hoc groups (like SCEP, SMIC and the Brookhaven symposium reported by Woodwell and Pecan) provide stimulating forums, but show the need for more sustained collaborative efforts. Just as GARP has provided a continuing coordination among meteorologists and climatologists, intergovernmental and nongovernment international organizations (UNESCO's Man and Biosphere, MAB, and ICSU's SCOPE) must rise to fill their natural roles in coordinating biosphere studies. In the U.S., in addition to ERDA, NSF, NOAA and NASA, various other agencies in the Departments of Agriculture and Interior will need to cocrdinate their important contributions in the form of data, monitoring, and research. Establishing and reinforcing really effective communication and cooperation among diverse organizations and disciplines will challenge the best efforts of all involved.

\subsection{Conclusions}

If the present predictions (Figs. 12 and 13) are anywhere near the truth, not long after the year 2000 the warming effect of increased atmospheric $\mathrm{CO}_{2}$ could become conspicuous above the "noise level" from other causes of climate fluctuation. However, the momentum of societal fuel use patterns may make it difficult then to adjust from fossil energy to nonfossil energy quickly enough to avoid eventualy severe consequences. Hence the time available for action may be quite limited.

Quite clearly we must improve our predictions of the consequences of increased atmospheric $\mathrm{CO}_{2}$. The largest uncertainty is the specific effect of a given increase on the regional climates of the world. As a consequence a first priority should be given to the study of possible climate changes. A better understanding of the carbon cycle is also needed to better project the rate of increase of atmospheric $\mathrm{CO}_{2}$. Finally, we must learn to project the impact of relativity rapid climatic changes on man, his environment and his society.

As the potential consequences of various scenarios of energy development become more clearly foreseeable, these must be included in the cost-benefit analyses. Depending upon their severity, it is to be expected that non- 
fossil fuel options such as fusion and breeder reactors for central station generation of electric power and wind, solar and geothermal energy for dispersed sources will be increasingly favored. One non-fossil fuel option that might be actively considered is the use of cultivated and waste biomass as fuel, perhaps with conversion to methanol, ethanol, methane and/or hydrogen. This could become an attractive solar energy conversion method that recycles atmospheric $\mathrm{CO}_{2}$.

While other actions that reduce the impact of climate change, such as the establishment of food reserves and the diversification of agriculture could be effective even if taken unilaterally by individual nations, actions that reduce the rate of production of anthropogenic $\mathrm{CO}_{2}$ depend strongly on multinational cooperation to be effective. If the severe economic and political repercussions that are possible on a world scale are to be avoided, a technological commitment must be made in the next few years; a world strategy arrived at with enlightment and wisdom. While humanity may not be able to foresee the future consequences of "the great experiment" clearly enough to control them, we cannot afford not to try! 


\section{References}

Attiwil1, P. M., 1971. "Atmospheric Caxbon Dioxide and the Biosphere," Environmental Pollution, 1: 249.

Averitt, P., 1975. "World Estimated Total Reserves of Coal," USGS Bulletin 1412, Washington, D.C.

Bazilevich, N. I., 1974. "Energy Flow and Biogeochemical Regularities of the Main World Ecosystems," in Proceedings First International Congress of Ecology, Pudoc, Wageningen, Netherlands, p. 182.

Bolin, B., 1970. "The Carbon Cycle," Scientific American, September, p. 125 .

Bolin, B., 1974. "Modeling the Climate and its Variations," Ambio, $3: 180$.

Botkin, D. B., J. F. Jonak and J. R. Wallis, 1973. "Estimating the Effects of Carbon Fertilization on Forest Composition by Ecosystem Simulation," in Carbon in the Biosphere, G. M. Woodwell and E. V. Pecan, eds., Conference 720510 , U.S.A.E.C., p. 328.

Bowen, H. J. M., 1966. Trace Elements in Biochemistry, Academic Press, New York, p. 52.

Broecker, W. S., 1974. Chemical Oceanography, Harcourt Brace Jovanovich, Inc., New York, p. 25.

Broecker, W. S., 1975. "Climate Change: Are We on the Brink of a Pronounced Global Warming?" Science, 189: 460.

Broecker, W. S. and Li, Y-H, 1970. "Interchange of Water Between the Major Oceans," Journal of Geophysical Research, 75(18): 3545.

Bunt, J. S., 1975. "Primary Productivity of Marine Ecosystems," in Primary Productivity of the Biosphere, H. Lieth and R. H. Whittaker, eds., Springer Verlag, New York, p. 169.

Burgess, R. L., 1975. "Forest Fuels and Energy Demand," Proceedings 55th Annual Meeting, Appalachian Section, Society of American Foresters, in press.

Burling, R. W., 1976. "An Overview Model of the $\mathrm{CO}_{2}$ Systems in the Atmosphere and Ocean," Office of Naval Research Conference on the Fate of Fossil Fuel Carbonates, January 19-23, Honolulu, Hawaii.

Caton, G. M., D. C. Michelson, B. Y. Barber, G. S. Danford, L. M. Frogge, R. J. Hanley, H. B. Morgan, J. W. Taylor, D. M. Weissberg, and C. F. Wilkes, 1976. "Inventory of Energy Research and Development: 19731975," Committee Print, Committee on Science and Technology, Serial $\mathrm{U}$, Jan. (5 Vols.), U.S. Government Printing Office, Washington, D.C. 
Charlson, R. J. and M. J. Pilat, 1969. "Climate: The Influence of Aerosols," Journal of Applied Meteorology, 8: 1001.

Duncar, D. C. and V. E. Swanson, 1965. "Organic-Rich Shale of the United States and World Land Areas," United States Geological Survey Circular 523, Waskington, D.C.

Earl, D. E., 1975. Forest Energy and Economic Development, Oxford: Clarendon Press.

ERDA, 1975. "Federal Inventory of Energy Related Biomedical and Environmental Research for FY 1974 and FY 1975," ERDA-110 (5 Vols.), National Technical Information Service, U.S. Department of Commerce, Springfield, Virginia.

Erikson, E. and P. Wellander, 1956. "On A Mathematical Model of the Carbon Cycle in Nature," Tellus 8(2): 155.

Flint, H. F., 1971. Glacial and Quaternary Geology, John Wiley Interscience, New York.

GARP, 1975. "The Physical Basis of Climate and Climate Modeling," Global Atmospheric Research Program, Publication 16, World Meterological Organization-International Congress of Scientific Unions, UNIPUB, New York.

Garrels, R. M., F. T. Mackenzie, and C. Hunt, 1975. Chemical Cycles and the Global Environment, William Kaufmann, Inc., Los Altos, California.

Gates, D. and R. Schmerl, 1975. Biophysical Ecology, Springer Verlag, New York.

Gribbin, J., 1976. "Antarctica Leads the Ice Ages," New Scientist, 69 (March): 695.

Ha11, C. A. S., C. A. Ekdah1, D. E. Wartenberg, 1975. "A Fifteen Year Record of Biotic Metabolism in the Northern Hemisphere," Nature 255(5504): 136.

Holland, H. D., 1972. "The Geologic History of Sea Water - An Attempt to Solve the Problem," Geochemica et Cosmochemica Acta, 36: 637.

Hubbert, M. K., 1974. "Estimate of the Ultimate World Production of Petroleum Liquids," Committee Print, Senate Committee on Interior and Insular Affairs, Serial No. 93-40 (92-75), U.S. Government Printing Office, Washington, D.C.

ICAS, 1974. "Report of the Ad Hoc Panel on the Present Interglacial," Federal Council for Science and Technology, Interdepartmental Committee for Atmosphere Science, National Science Foundation, ICAS 18b-FY75. 
IEA, 1976. "The Implication of a U.S. Moratorium," Institute for Energy Analysis, Study in Progress, Oak Ridge, Tennessee.

Keeling, C. D., 1968. "Carbon Dioxide in Surface Ocean Waters," Journal of Geophysical Research, 73(14): 4543.

Keeling, C. D., 1973a. "Industrial Production of Carbon Dioxide from Fossil Fuels and Limestone," Tellus 25: 174.

Keeling, C. D., 2973b. "The Carbon Dioxide Cycle: Reservoir Models to Depect the. Exchange of Atmospheric Carbon Dioxide with the Oceans and Land Plants," ir Chemistry of the Lower Atmosphere, S. I. Rasool, ed., Plenum Press, New York, p. 251.

Keeling, C. D., 1976. "Impact of Industrial Gases on Climate," Energy and Climate: Outer Limits to Growth, Geophysics Study Committee, Geophysics Research Board, National Academy of Sciences, Washington, D.C., in press.

Keeling, C. D., R. B. Bacastow, A. E. Bainbridge, C. A. Ekdahl, Jr., P. R. Guenther, L. S. Waterman, and J. F. S. Chin, 1976. "Atmospheric Carbon Dioxide Variations at Mauna Loa Observatory, Hawaii," Tellus, in press.

Koblentz-Mishke, J. J., V. V. Volkovinsky, and J. G. Kabanova, 1970. "Plankton Primaxy Production of the World Ocean," in Scientific Exploration of the South Pacific, W. S. Wooster, ed., National Academy of Science, Washington, D.C., p. 183.

Kovda, V. A. and I. V. Yakushevaskayc, 1971. "Biomass and Soil Humus She11," in Biosphere and Its Resources, Publishing House "Nauka," Moscow, p. 132 .

Li, Y-H, 1972. "Geochemical Mass Balance Among Lithosphere, Hydrosphere, and Atmosphere," American Journal of Science, 272: 119.

Lieth, H. and R. H. Whittaker, 1975. "Primary Productivity of the Biosphere," Ecological Studies 14, Springer Verlag, New York.

MacKenzie, F. T., and R. M. Garrels, 1966. "Chemical Mass Balance Between Rivers and Oceans," American Journal of Science, 264: 507.

Mitchell, J. M., Jx., 1961. "Recent Secular Changes of Global Temperature," Annals of the New York Academy of Science, 95: 235.

Mitche11, J. M., 1971. "The Effect of Atmospheric Aerosols on Climate with Special Reference to Temperature Near the Earth's Surface," Journal of Applied Meteorology, 10: 703.

Mitche11, J. M., Jr., 1972. "The Natural Breakdown of the Present Interglacial and Its Possible Intervention by Human Activities," Quaternary Research, 2: 436 . 
Mitche11, J. M., Jr., 1973. "A Reassessment of Atmospheric Pollution As A Cause of Long-Term Changes of Global Temperature," in The Changing Global Environment, S. F. Singer, ed., D. Reidel Publishing Company, Dordrecht-Holland/Boston, USA, p. 149.

NAS, 1975. "Understanding Climate Change, A Program for Action," U.S. Committee for the Global Atmospheric Research Program, National Academy of Sciences, Washington, D.C.

Oeschger, H., U. Siegenthaler, U. Schotterer, and A. Gugelmann, 1975. "A Box Diffusion Model to Study the Carbon Dioxide Exchange in Nature," Tellus $27(2): 168$.

01son, J. S., 1970a. "Carbon Cycles and Temperate Woodlands," in Analysis of Temperate Forest Ecosystems, D. E. Reichle, ed., Springer Verlag, New York.

01son, J. S., 1970b. "Continenta1 Ecosystem Patterns and Reconstructed Living Carbon Prior to Iron Age," (Map inside back cover) in Analysis of Temperate Forest Ecosystems, D. E. Reichle, ed, Springer Verlag, New York.

Olson, J. S., 1976. "Ecological Simulations: Biospheric Operations Research and the Carbon Cycle," presented before Operations Research Society of America, Dallas, Texas, May 197I: manuscript in preparation.

Poldervaart, A., 1955. "Chemistry of the Earth's Crust," in Crust of the Earth, Geological Society of America Special Paper 62, p. 119.

Reiners, W. A., L. H. Allen, Jr., R. Bacastow, D. H. Ehalt, C. S. Ekdah1, Jr., G. Likens, D. H. Livingston, J. S. Olson, and G. M. Woodwel1, 1973. "A Summary of the World Carbon Cycle and Recommendations for Critical Research," in Carbon ana the Biosphere, G. M. Woodwell and E. V. Pecan, eds., Conference 720510 , U.S.A.E.C., p. 368.

Revelle, R., and H. E. Suess, 1957. "Carbon Dioxide Exchange Between the Atmosphere and Ocean, and the Question of an Increase in Atmospheric $\mathrm{CO}_{2}$ During the Past Decades," Tellus, 9(1): 18.

Rotty, R. M., 1973. "Comnentary on and Extension of Calculation Procedure for $\mathrm{CO}_{2}$ Production," Tellus, 25(5): 508 .

Rotty, R. M., 1976. "Global Carbon Dioxide Production from Fossil Fuels and Cement, A.D. 1950-A.D. 2000," Office of Naval Research Conference on the Fate of Fossil Fuel Carbonates, January 19-23, Honolulu, Hawaii.

Rubey, W. W., 1951. "Geologic History of Seawater, An Attempt to State the Problem," Geological Society of America Bulletin, 62: 1111.

Rubey, W. W., 1955. "Development of the Hydrosphere and Atmosphere with Special Reference to Probable Composition of the Early Atmosphere," in Crust of the Earth, Geological Society of America Special. Paper 62, p. 631 . 
Ryther, J. H., 1969. "Photosynthesis and Fish Production in the Sea," Science, 166: 72 .

SCEP, 1970. "Man's Impact on the Global Environment, Assessment and Recommendations for Action," Study of Critical Environment Problems, MIT Press, Cambridge, Massachusetts.

Schneider, S. H., 1975. "On the Carbon Dioxide - Climate Confusion," Journal of Atmospheric Science, 32: 2060.

Schneider, S. H. and C. Mass, 1975. "Volcanic Dust, Sunspots, and Temperature Trends," Science, 190: 741.

Shugart, H. H., Jr., and D. C. West, 1976. "Development of an Appalachian Deciduous Forest Succession Model and Its Application to Assessment of the Impact of Chestnut Blight," Submitted to Journal of Ecology.

Sillén, L. G., 1963. "How Has Sea Water Got Its Present Composition?" Svensk Kemisk Tidskrift, $75(4): 161$.

SMIC, 1971. "Inadvertant Climate Modification," Report of Study of Man's Impact on Climate, MIT, Cambridge, Massachusetts.

Spofford, W. 0., Jx., 1971. "Decision Making Under Uncertainty: The Case of Carbon Dioxide Buildup in the Atmosphere," in Man's Impact on the Climate, W. H. Mathews, W. W. Kellogg, and G. D. Robinson., eds., MIT Press, Cambridge, Massachusetts, p. 537.

Strickland, J. D. H., 1965. "Production of Organic Matter in the Primary Stages of the Marine Food Chain," in Chemical Oceanography, J. P. Riley and G. Skirrow, eds., Academic Press, p. 478.

Stuiver, M., 1973. "The ${ }^{14} \mathrm{C}$ Cycle and Its Implications for Mixing Rates in the Ocean-Atmosphere System," in Carbon in the Biosphere, G. W. Woodwell and E. V. Pecan, Conference 720510 , U.S.A.E.C., p. 6 .

United Nations, 1955. "World Energy Requirements in 1975 and 2000," Peaceful Uses of Atomic Energy (International Conference on the Peaceful Uses of Atomic Energy) Vo1. 1, United Nation's Department of Economic and Social Affairs, New York, pp 3-33.

United Nations, 1975. World Energy Supplies 1970-1973, Statistical Office, U.N. Department of Economic and Social Affairs, New York.

Wangersky, P. J., 1972. "The Cycle of Organic Carbon in Sea Water," Chimia 26(11): 559.

Whittaker, R. H., 1975. Communities and Ecosystems, 2nd Ed., MacMillan, New York.

Woodwell, G. M., and E. V. Pecan, eds., 1973. Carbon in the Biosphere, Conference 720510 , U.S.A.E.C. 
Woodwe.1, G. M., P. H. Rich, and C. A. S. Ha11, 1973. "Carbon in Estuaries," in Carbon in the Biosphere, G. M. WoodweII and E. V. Pecan, eds, Conference 720510 , U.S.A.E.C., p. 221. 